\title{
Non-destructive on-chip imaging flow cell-sorting system for on-chip cellomics
}

\author{
Kenji Yasuda $\cdot$ Akihiro Hattori · Hyonchol Kim • \\ Hideyuki Terazono $\cdot$ Masahito Hayashi $\cdot$ Hiroyuki Takei • \\ Tomoyuki Kaneko $\cdot$ Fumimasa Nomura
}

Received: 11 April 2012/ Accepted: 11 October 2012/Published online: 5 December 2012

(C) The Author(s) 2012. This article is published with open access at Springerlink.com

\begin{abstract}
We have developed a non-destructive imaging flow cell-sorting system using an ultra-high-speed camera (shutter speed of $1 / 10,000 \mathrm{~s}$ ) with a real-time image analysis unit and a poly(methyl methacrylate) (PMMA)-based disposable microfluidic chip for single-cell-based on-chip cellomics. It has a 3-D micropipetting device that supports fully automated sorting and collection of samples. The entire fluidic system is implemented in a disposable plastic chip, enabling biological samples to be lined up in a laminar flow using hydrodynamic focusing. Its optical system enables direct observation-based cell identification using specific image indexes and phase-contrast/fluorescence microscopy, real-time image processing. It has a nondestructive, wider dynamic range, sorting procedure using mild electrostatic force in a laminar flow; agarose gel electrodes are used to prevent electrode loss and electrolysis bubble formation. The microreservoir used for recultivating collected target cells is contamination-free. An integrated ultra-high-speed droplet polymerase chain reaction measurement module is used for DNA/mRNA analysis of the collected target cells. This system was used
\end{abstract}

\footnotetext{
K. Yasuda $(\bowtie) \cdot$ A. Hattori · T. Kaneko · F. Nomura

Institute of Biomaterials and Bioengineering,

Tokyo Medical and Dental University,

2-3-10 Kanda-Surugadai, Chiyoda,

Tokyo 101-0062, Japan

e-mail: yasuda.bmi@tmd.ac.jp

K. Yasuda $\cdot$ H. Kim · H. Terazono · M. Hayashi · H. Takei

Kanagawa Academy of Science and Technology,

3-2-1 Sakado, Takatsu, Kawasaki 213-0012, Japan

H. Takei

Faculty of Life Sciences, Toyo University,

1-1-1 Izumino, Itakura-cho, Oura-gun,

Gunma 374-0193, Japan
}

to separate cardiomyocyte cells from a mixture of various cells. All the operations were automated using the 3-D micropipetting device. The results demonstrate that this imaging flow cell-sorting system is practically applicable for biological research and clinical diagnosis.

Keywords Imaging cytometry · On-chip imaging flow cell sorting · Poly(methyl methacrylate) (PMMA) disposable chip - Agarose gel microelectrode . On-chip cellomics - Cardiomyocytes - Cell recultivation . Polymerase chain reaction (PCR) analysis

\section{Introduction}

In general, a cell is the minimum unit with self-determined responses based on genetic and epigenetic information, e.g., their interaction histories, and based on fluctuations in its environmental conditions. If we are to understand such things as the variations between cells with identical genetic information, the inheritance of non-genetic information from the previous cell generation, the adaptation of cells to environmental change, and the community effect of cells, we need to analyze, using identified single cells, their epigenetic information, starting from twin complementary viewpoints of cell regulation: as an 'algebraic' system with emphasis on the temporal aspects, such as adaptation from one generation to the next, and as a 'geometric' system with emphasis on spatial aspects, such as the spatial pattern-dependent community effect.

We are conducting a series of studies to analyze epigenetic information in sequential cell generations and in the spatial structures of cell networks to expand our understanding of how the fates of living systems are determined. Our objective is the development of a system 
for disposable contamination-free recultivation that can be operated simply and safely in both research and clinical settings. To facilitate our efforts, we have developed an on-chip microfabrication method that is based on a strategy we call "on-chip cellomics." As shown in Fig. 1, it comprises three steps. First, cells from tissue are purified one by one in a non-destructive manner (Yasuda 2000). The cells are then cultivated and observed under fully controlled conditions (i.e., the cell population, the network pattern, and the nutrient conditions are controlled) using an on-chip single-cell cultivation chip (Inoue et al. 2001a, b, 2004; Wakamoto et al. 2001, 2003; Umehara et al. 2003; Takahashi et al. 2003; Hattori et al. 2003; Matsumura et al. 2003a, b) or an on-chip agarose microchamber system (Moriguchi et al. 2002, 2004; Hattori et al. 2004; Sugio et al. 2004; Suzuki et al. 2004a,b; Kojima et al. 2003, 2005). Finally, single-cell-based genome/proteome analysis is performed using photothermal denaturation and single-molecule-level analysis (Yasuda et al. 2000).

The purification of particular target cells from a crude sample mixture of cells is the first and most important step for on-chip experiments. Efficient and rapid purification of cells has been accomplished with techniques such as fluorescence-activated cell sorting (FACS) (Ogawa et al. 1994; Hulett et al. 1973; Bonner et al. 1972; Herzenberg and Sweet 1976; Assenmacher et al. 1995; Johnson et al. 2007), magnetic-activated cell separation (MACS) (Imamura et al. 1995; Owen and Sykes 1984; Zborowski and Chalmers 2005, 2011), automated single-cell sorting using dual-beam optical trapping (Grover et al. 2001), differential adhesion cell sorting (Hsu et al. 2008), and disposable microfabricated fluorescence-activated cell sorting ( $\mu$ FACS) (Liu et al. 2011; Yoon et al. 2011; Azuma et al. 2007). In addition, recent advancements in optofluidic flow cytometry, in which optics and microfluidics are used together to create novel functionalities on a small chip, hold great promise for lab-on-a-chip flow cytometry (Yasuda et al. 2006; Hatayama et al. 1994). The development of a low-cost, compact, handheld flow cytometer and $\mu$ FACS system would have a significant impact on pointof-care diagnostics and thereby improve health care.

In measurements using a conventional flow cytometer, the target cells for FACS are usually labeled with fluorescent dyes using specific antibodies or other molecules, and the optical signals (angular light scattering or emitted fluorescence) are detected and analyzed to identify individual cells or biological samples. These tools greatly facilitate the study of both the physical properties (e.g., size, shape) and biochemical properties (e.g., cell cycle distribution, DNA contents) of biological samples such as cells. Information about the cells of interest is obtained optically in a non-destructive and quantitative manner (Yamashita et al. 2007; Takahashi et al. 2006).

However, FACS can damage cells during droplet generation, and detection based on non-direct scattering in principle carries the risk of poor cell recognition. If the cells are to be used for cultivation after purification, cell damage due to sorting must be minimized. MACS, e.g., enables cells to be easily separated by incubating them with magnetic particles coated with antibodies against a particular surface antigen. This incubation promotes the attachment of cells expressing a specific antigen for the magnetic particles. The cell solution is then transferred into a column placed in a strong magnetic field. The cells attached to the particles (expressing the antigen) remain in the column, while the other cells (not expressing the antigen) flow out. While this method is simple and economical, the attached antibodies are difficult to remove from the cell surface and can change the properties of the target cells. Other conventional techniques also have disadvantages with respect to cost, efficiency, response speed, separation resolution, and/or adaptability.

In contrast, $\mu \mathrm{FACS}$ offers several advantages, including reduced sample volume, shorter handling time, smaller space requirement, and less operational cost. In particular, the smaller space required and potential lower cost of a $\mu$ FACS system would make it more portable and affordable, which are particularly important to individual laboratories and point-of-care clinics. There are three core components of a $\mu \mathrm{FACS}$ system that need to be
Fig. 1 On-chip cellomics: onchip single cell-based analysis of cellular networks temporally and spatially

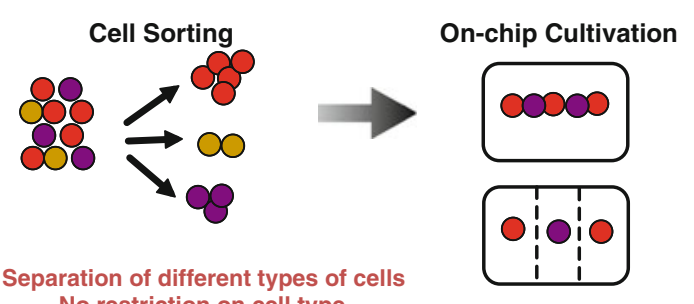

No restriction on cell type No-need for precultivation

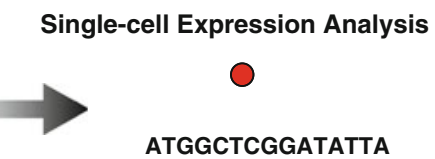

Single-cell expression data reflecting time dependency, community effect, etc. 
miniaturized while maintaining performance: (1) the fluidic system for introduction and placement of biological samples, (2) the optical system for illumination of samples and collection of emitted light (both scattered and fluorescent), and (3) the sorting system for collection of samples of interest, which requires both real-time control and a rapidresponse actuation system. The key challenge to developing a high-performance $\mu$ FACS system is to figure out how to reduce the volume and cost of these three components while maintaining adequate performance (e.g., detection sensitivity and sorting throughput).

However, even if such a $\mu$ FACS system were developed, it would be hard to apply it to non-invasive collection of target cells due to its use of fluorescent antibodies for labeling and identifying target cells. To achieve the above advantages and to promote deeper penetration of current flow cytometry technology into the clinical area, a detection method must be developed that does not rely on fluorescence-based target detection so that cells can be detected without seriously damaging them.

One approach to overcoming this labeling problem is to use optical microscope images instead of fluorescent intensities to identify target cells from the morphological viewpoint. Various challenges have been met and overcome, and target cells have been detected using optical images without any labeling, both in vitro (Schonbrun et al. 2012) and in vivo (Golan et al. 2012). These studies were limited in terms of imaging flow cytometry, i.e., a cellsorting function was not included, so the next step is to develop an imaging cell-sorting system in which target cells are recognized and sorted using morphological characteristics like cell size for the collection of label-free intact cells.

As a step towards achieving such a system, we have developed an on-chip high-speed imaging cell-sorting system for label-free collection of cells (Takahashi et al. 2004; Hattori and Yasuda 2010; Sawaki et al. 2007). The developed system has five core features: (1) fully automated sorting and collection of samples using a 3-D micropipetting device, (2) arrangement of the entire fluidic system in a disposable plastic chip, enabling biological samples to be lined up in a laminar flow using hydrodynamic focusing, (3) direct observation-based cell identification using specific image indexes and an optical system comprising phase-contrast/fluorescence microscopy and real-time image processing, (4) non-destructive wider dynamic range sorting using mild electrostatic force in a laminar flow (agarose gel electrodes are used to prevent electrode loss and electrolysis bubble formation), and (5) contamination-free recultivation of collected target cells in a microreservoir. The most important characteristics of this system are real-time image processing and the sorting of target cells on the basis of morphological indexes (e.g., cellular area or perimeter). The system also has a fluorescence detection unit, so cells can be sorted using a combination of image processing and conventional fluorescence detection. The cells are separated by applying a mild electrostatic force to only those cells to be removed for disposal; i.e., the targeted cells remain in the laminar flow and do not receive any stimulation from the electrostatic force.

In this paper, we describe the concept and present a complete picture of our automated imaging flow cell-sorting system. We do this by summarizing previously reported descriptions and data and presenting new descriptions and data that together give an overall picture of the integrated systems. We also discuss potential improvements that overcome the limitations of existing technologies.

\section{Fully automated on-chip imaging flow cell-sorting system}

Cell sorting is a target-cell purification technology consisting of (1) sample cell preparation, (2) target cell identification, (3) target cell collection, and finally (4a) recultivation of target cells or (4b) analysis of cells such as by DNA/mRNA analysis, protein analysis, or functional measurement (Fig. 2). Target cell identification and target cell acquisition are two major areas in cell-sorting technology development. The post-cell-sorting procedures (recultivation or analysis) should also be included in an integrated cell-sorting system.

For the purpose of non-invasive target cell identification and target cell acquisition, we have developed a fully automated system for on-chip imaging flow cell sorting (Hayashi et al. 2011a). As shown in Fig. 3, it comprises (1) a cell-sorting chip attached to a cell-sorting chip holder, (2) a holder for sample tubes and collection tubes, (3) an

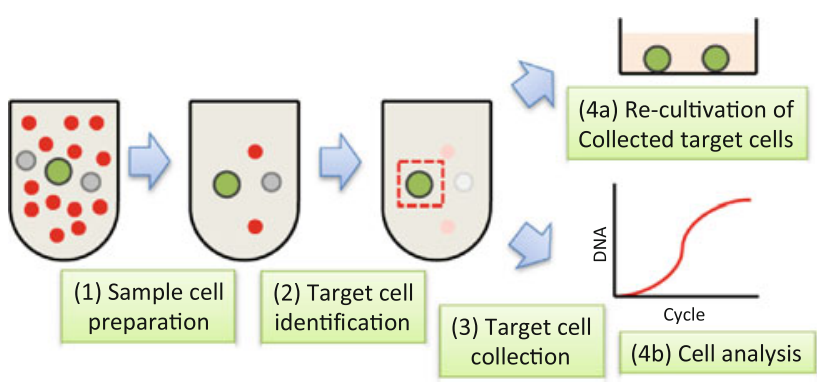

Fig. 2 Cell sorting procedure in fully automated on-chip imaging flow cytometry system: 1 cells in a crude sample mixture are dispersed and roughly purified using conventional preparation method, 2 target cells are identified on the basis of their configuration information, 3 identified cells are collected, and $4 a$ identified target cells are recultivated for further experimentation or $4 b$ used for analysis 
automatic 3-D motion pipetting device $(60 \times 20 \mathrm{~cm}$ motion in $x-y$ plane, and $20 \mathrm{~cm}$ motion in $z$ axis), (4) a holder for pipetting chips, (5) an ejection port for used pipetting chips, (6) an air pressure unit connected to a syringe pump, (7) an automatic alignment set of phasecontrast/fluorescent optical microscopy modules, (8) an image-processing unit consisting of a high-speed camera and an image-processing and system control computer, and (9) a switching DC power supply.

\section{Cell-sorting chips}

\subsection{Design}

We tested two previously reported types of cell-sorting chips made of PMMA-based plastic (Hayashi et al. 2011a; Hattori et al. 2011; Takahashi et al. 2004): a two-way outlet chip (Fig. 4a-c) and a three-way-outlet chip (Fig. 4d-f). Both types have inlet pathways for the sample and buffer flows, hydrodynamic-focusing pathways, a cell-sorting area where the sample and buffer flows join together while maintaining their respective boundaries, gel channels (a pair of agarose microelectrode storage spaces) attached to the cell-sorting area, and outlet pathways for the target samples and waste samples. The cell-sorting area was $50 \mu \mathrm{m}$ wide by $25 \mu \mathrm{m}$ high. The two agarose microelectrode storage spaces were filled with $1 \%$ sol-state agarose containing $0.5 \mathrm{M} \mathrm{NaCl}$ as electrolyte. The use of this electroconductive solvent to form the electrodes prevented electrolysis bubble formation. The layer of PMMA film on the bottom of each chip was $100 \mu \mathrm{m}$ thick (which is within the depth of focus of $\mathrm{a} \times 100$ objective lens) and was attached to the chip by heat bonding.

The agarose was injected into the gel inlets immediately before each trial. Small acrylic tubes were attached to both the sample inlet and outlet for chip collection, and large acrylic tubes were attached to the inlet area upstream and to the outlet area downstream to serve as a buffer reservoir (Fig. 4g-h). In the two-way-outlet chip, a raw sample was introduced from the sample reservoir into one of the two microfluidic pathways fabricated in the chip, and a voltage was applied to the gel microelectrode storage spaces to shift the cells to the other buffer pathway. In the three-wayoutlet chip, a raw sample was introduced from the sample reservoir into the center pathway, and an appropriate
Fig. 3 Fully automated onchip imaging flow cytometry system with disposable contamination-free plastic recultivation chip: a schematic diagram, b photograph (reproduced from Hayashi et al. 2011a) (a)

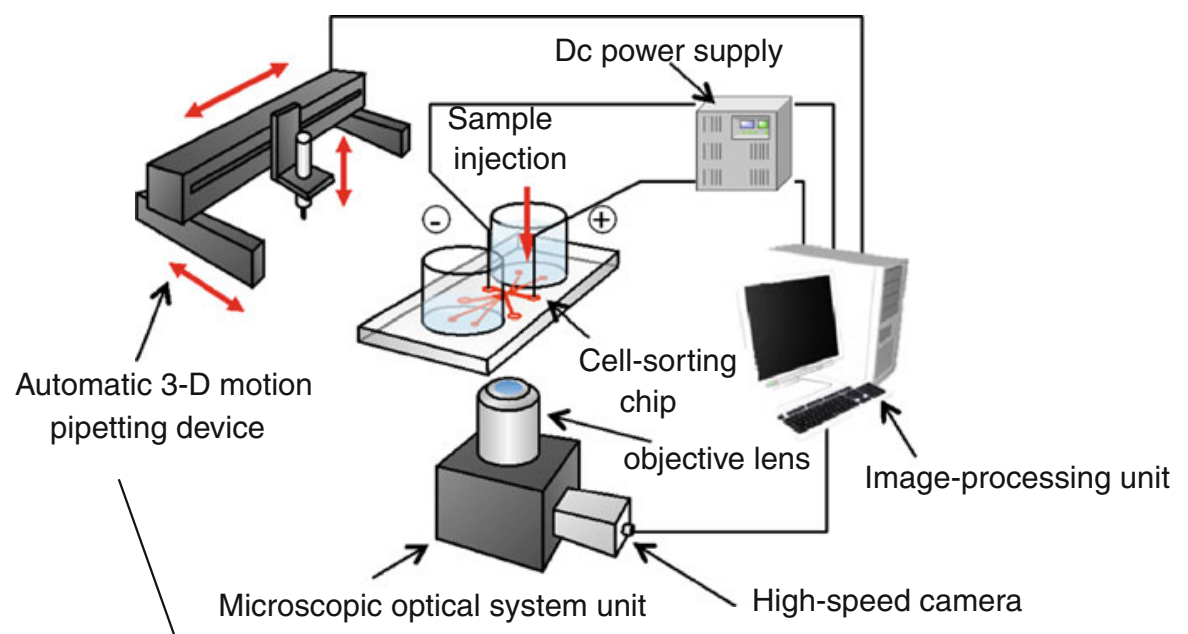

Automatic 3-D motion pipetting device

(b) 
(a)

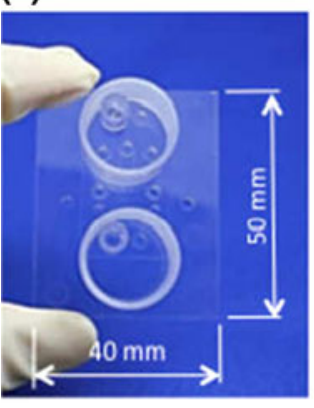

(d)

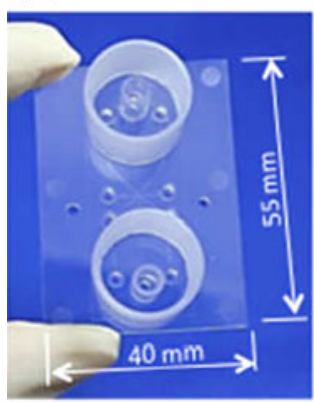

(b)

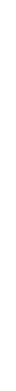

(e)

(e)

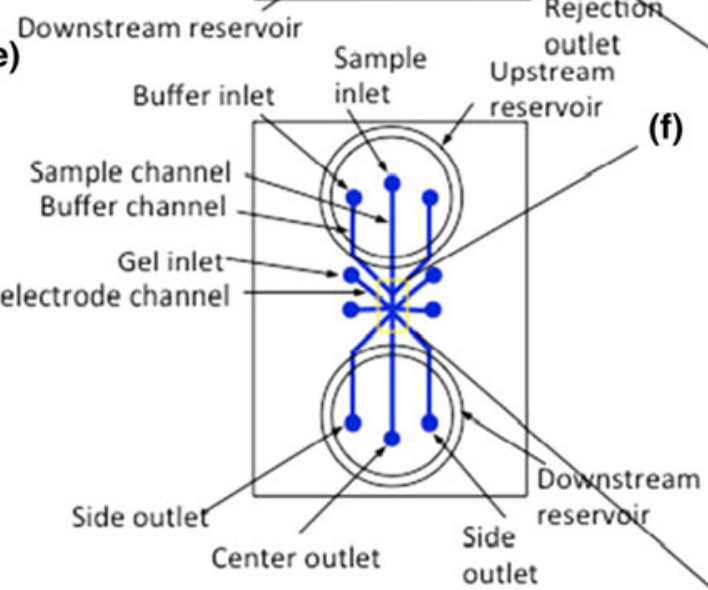

(h) (c)

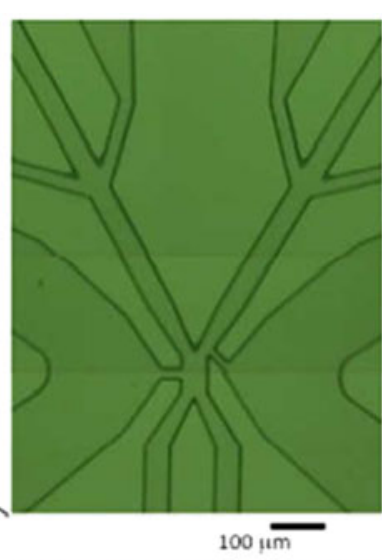

(f)

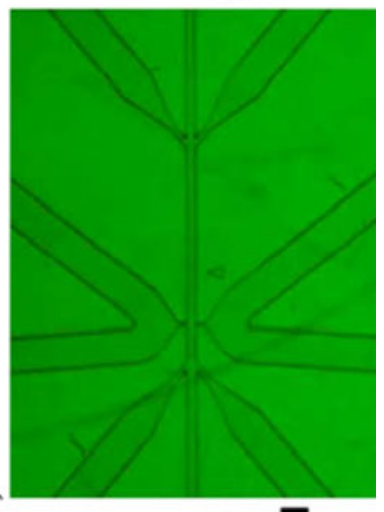

100 uт

(g)

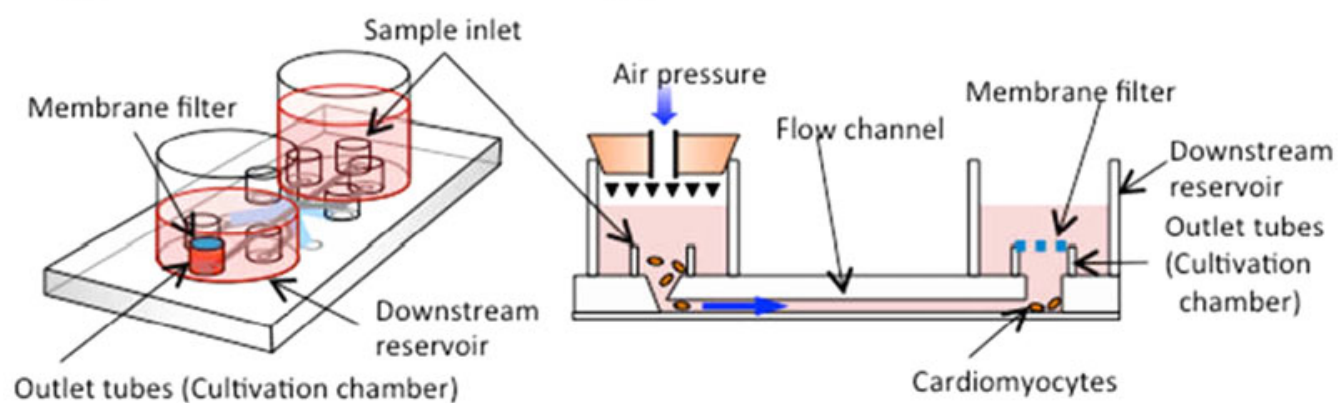

Fig. 4 Two- $(\mathbf{a}-\mathbf{c})$ and three- $(\mathbf{d}-\mathbf{f})$ way-outlet cell-sorting chips. Photographs (a and $\mathbf{d})$, schematic images (b and e), and magnified images (c and f) of chips. $\mathbf{g}$ Overall view and $\mathbf{h}$ side view of a recultivation chip (reproduced from Hayashi et al. 2011a; Hattori et al. 2011)

voltage was applied to the gel electrodes to shift the cells to the left or right laminar buffer flow.

\subsection{Fabrication}

We selected poly(methyl methacrylate) (PMMA) as the base material for both types of cell-sorting chips due to its visible light transparency, low self-fluorescence, easy disposability after use, compatibility with glue-free heat bonding, ability to be flexibly formed by heat, hydrophilicity in a microfluidic pathway, and cost efficiency. As shown in Fig. 5a-c, PMMA has a high transmittance ( $\sim 90 \%$ ) in the range of visible light from 400 to $600 \mathrm{~nm}$, which is approximately the same as that of a glass slide and a polycarbonate culture dish.

We first investigated the use of hot embossing to mold the chips. As shown in Fig. 5d, the fabricated microchannels had rounded edges and did not reflect the detailed edge structures of the microfluidic pathways in microscopic resolution. This was because the PMMA was not soft enough to permeate into the edges of the square-shaped microchannels at the temperature used in the hot embossing process. Then, as an alternative, we investigated the use of injection molding for the same microchannel design used for the hot embossing. The edge structures of the microchannels were improved-they had a sharp square 
(a)

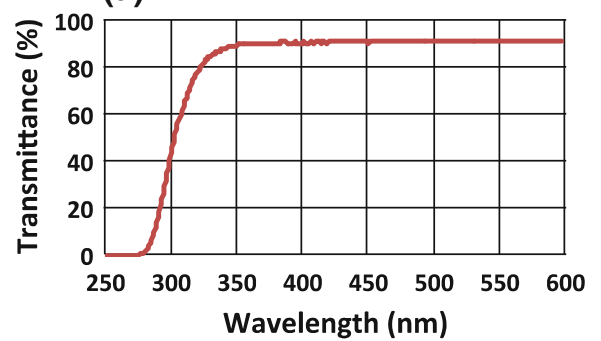

(d)

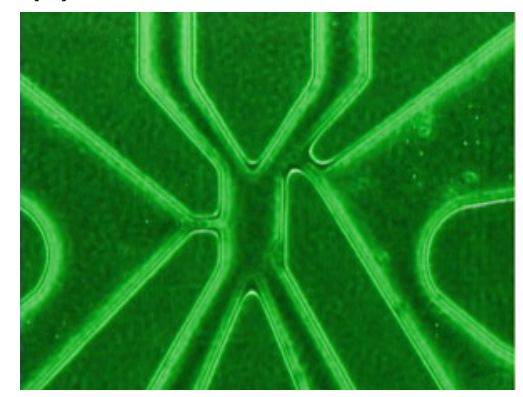

(b)

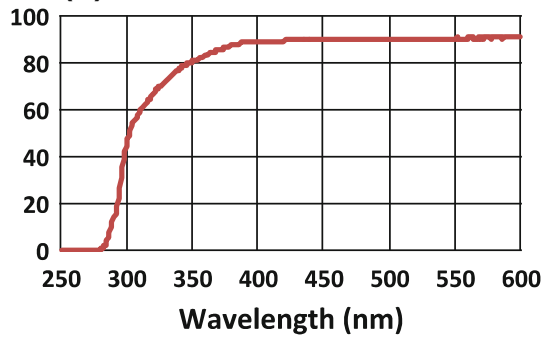

(e)

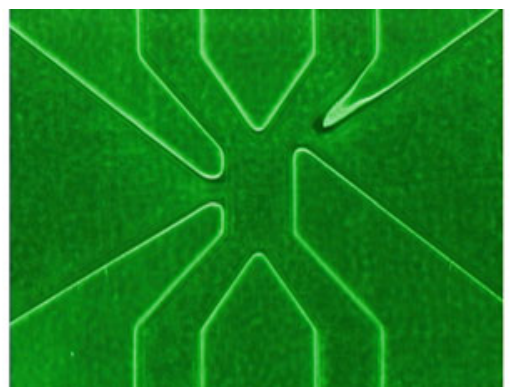

(c)

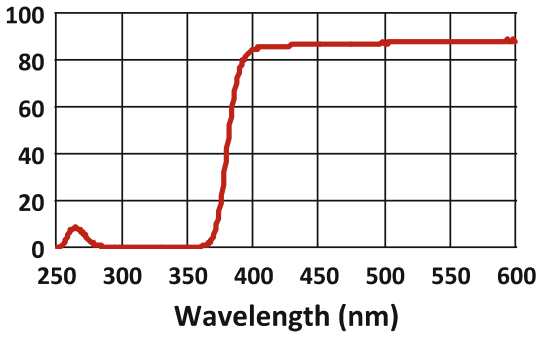

(f)

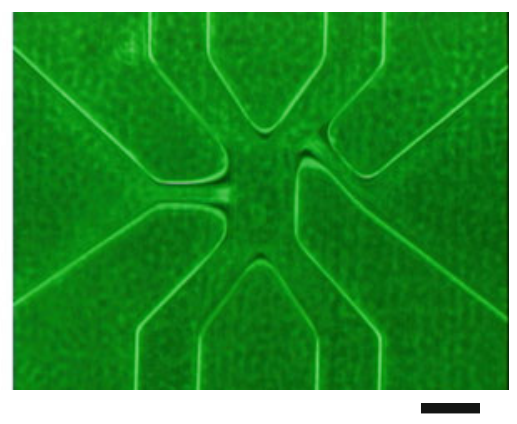

$50 \mu \mathrm{m}$
Fig. 5 Transmittance of $\mathbf{a}$ a glass slide, $\mathbf{b}$ a polystyrene culture dish, and c a PMMA sample plate $1 \mathrm{~mm}$ thick. Magnified images of PMMA-based cell-sorter chip fabricated by $\mathbf{d}$ hot embossing molding

shape. However, the melted PMMA resin did not permeate into the thin wall structure at the junction of the flow channels and gel channels (Fig. 5e). We thus redesigned the injection mold to thicken the wall structure by adding narrow channels ( $15 \mu \mathrm{m}$ wide; $45 \mu \mathrm{m}$ long) between the flow channels and gel channels (Fig. 5f). This enabled the PMMA resin to permeate deep into the walls around all the microchannels, resulting in junctions with a fine structure. This new design was used for the cell-sorter chips. The flow channel in the cell-sorting area was $50 \mu \mathrm{m}$ wide and $25 \mu \mathrm{m}$ high. The molded PMMA plate was sealed with a thin PMMA sheet $(100 \mu \mathrm{m}$ thick $)$ by hot lamination without glue.

\subsection{Spontaneous filling of agarose solution}

To enable filling of the agarose into the microchannels, the chip was preheated on a hot plate at $42{ }^{\circ} \mathrm{C}$ for $5 \mathrm{~min}$. A melted solution of $1 \%$ agarose and $0.5 \mathrm{M} \mathrm{NaCl}$ was then loaded into the gel inlets. Unlike with the poly(dimethylsiloxane) (PDMS)-based microfluidics chip previously reported (Hattori and Yasuda 2010; Sawaki et al. 2007), the melted gel spontaneously permeated into the gel channels due to capillary action-additional pressure was not required. The injected solution flowed around the junctions of the flow channels and gel channels, permeated the narrow channel structure, and stopped flowing at the tip of the and e, $\mathbf{f}$ injection molding. Chip shown in (f) had added narrow channels between flow channels and gel channels (adapted from Hayashi et al. 2011a)

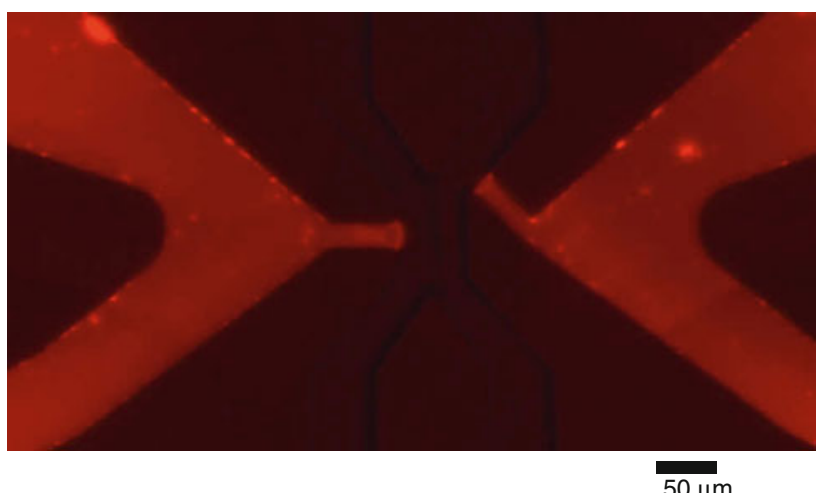

Fig. 6 Filling of agarose electrode gel in microelectrode structure. Agarose was labeled with fluorescent dye (Rhodamine B) for clear visualization, and a fluorescent image of the cell-sorting area was captured (reproduced from Hayashi et al. 2011a)

narrow channel. The agarose solution became a gel as it cooled at room temperature, and the gel remained filled to the edges of the flow channels (Fig. 6). This spontaneous permeation is attributed to the PMMA having higher wettability than PDMS.

Channel length was an important factor in the complete filling of the agarose solution to the flow channel edges. Channels that were $70 \mu \mathrm{m}$ or shorter were completely filled (Fig. 7a, b), while those that were longer than $70 \mu \mathrm{m}$ had portions that were not filled (Fig. 7c). 

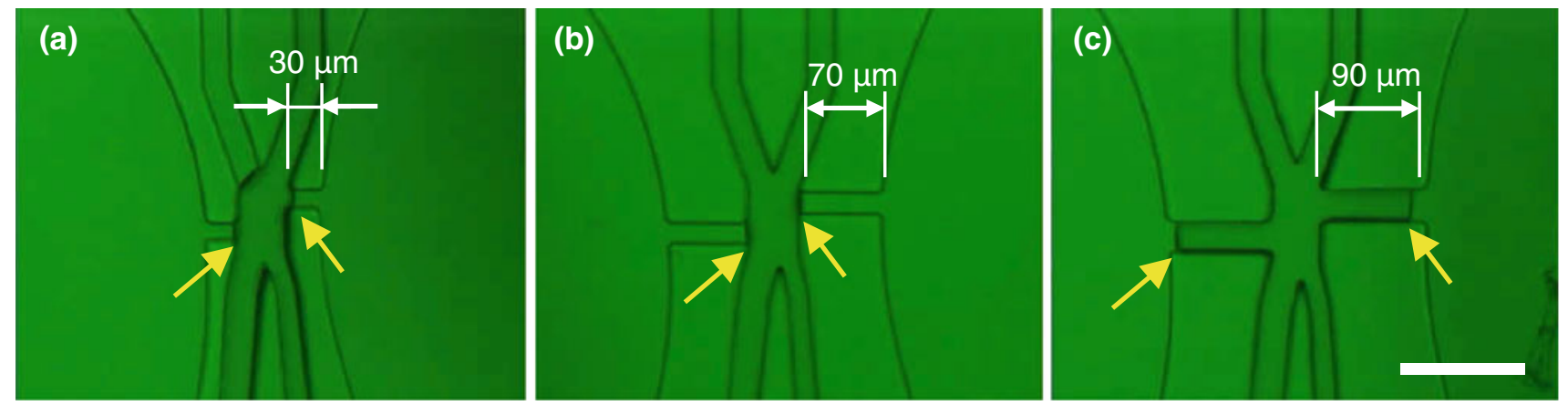

Fig. 7 Effect of flow channel length on precise control of gel electrode edge position: a $30 \mu \mathrm{m}, \mathbf{b} 70 \mu \mathrm{m}$, and $\mathbf{c} 90 \mu \mathrm{m}$. Yellow arrows indicate tips of agarose gel electrodes in gel channel. Scale bar $100 \mu \mathrm{m}$ (reproduced from Hattori and Yasuda 2010)
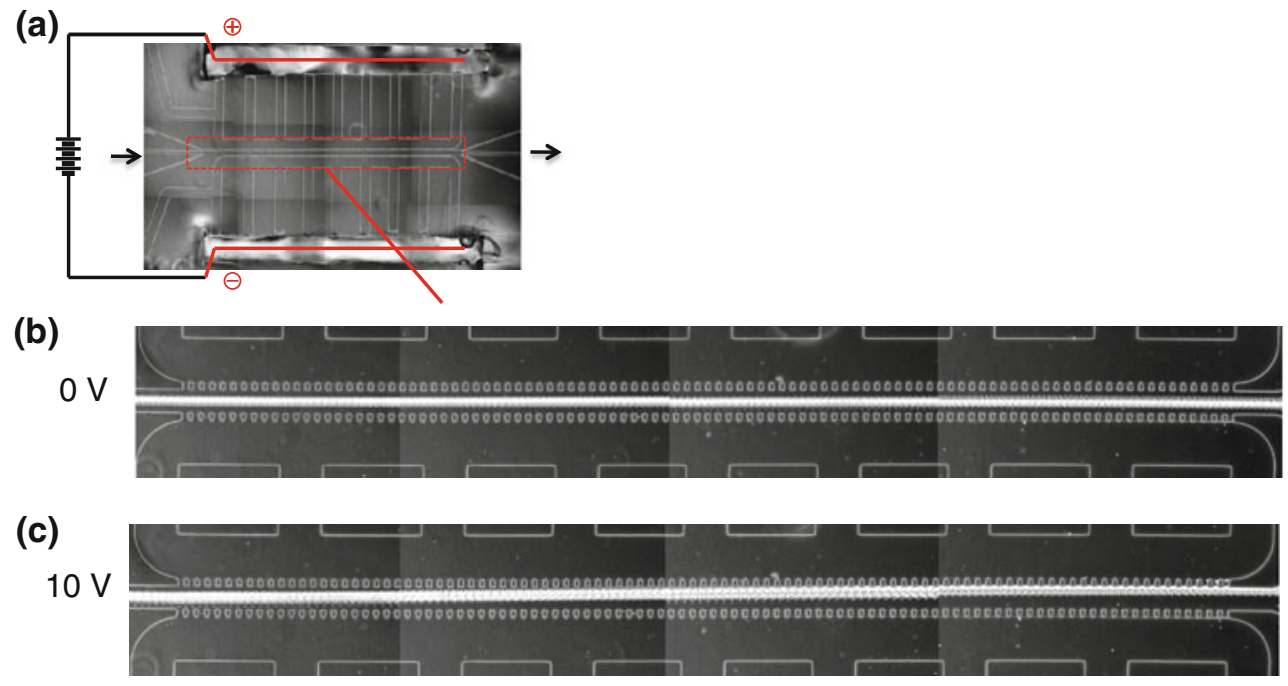

Fig. 8 100-step gel electrode array in microfluidic flow channel on a chip. a Array overview. In three-way-outlet sorting chip (see Fig. 4d-f), a 100-step gel electrode array was arranged on both side walls of a microfluidic pathway. b, c Continuous shift of cell flow pathway using the array. Time-course movements of human promyelocytic leukemia cells (HL60) were taken and overlapped. Cell flow pathways are shown

The technique described above for forming gel electrodes in the microfluidic flow channels can be easily expanded for use in forming an array of electrodes to increase the effective area of electrostatic force irradiation. As shown in Fig. 8, 100 pairs of $15-\mu \mathrm{m}$ wide gel electrodes were arranged with a $35-\mu \mathrm{m}$ interval in a three-way-outlet sorting chip. The pathway of flowing living cells was continuously shifted by sequential application of electrostatic force to the electrode array (Fig. 8c).

\subsection{Cell-sorting process}

The cell-sorting process begins with cell separation. An electric field created by DC voltage is used to generate electrostatic force in the cell-sorting area, causing cells to as white lines. $\mathbf{c}$ When $10 \mathrm{~V} \mathrm{DC}$ was applied to gel electrodes, cells shifted to anode gel electrode array wall because cell surface had a negative charge in general. Agarose gel containing $0.5 \mathrm{M} \mathrm{NaCl}$ formed electrolyte. Width of electrode was $15 \mu \mathrm{m}$, and gap between electrodes was $35 \mu \mathrm{m}$. Scale bar $200 \mu \mathrm{m}$

move from one laminar flow to another. As cells usually are charged negatively in water, the plus charge gel electrode is set at the cell collection streamline side. The use of agarose gel electrodes enables a high voltage to be applied between a pair of electrodes without bubble formation due to electrolysis. However, heat generation in an agarose gel electrode is problematic because its melting point is about $80{ }^{\circ} \mathrm{C}$. Application of a high voltage to the gel electrodes could cause them to melt. This means that selection of the electrolyte component is important.

To select a suitable electrolyte, we estimated the resistance $(\Omega / \mathrm{mm})$ of an agarose gel electrode containing various types of $0.5 \mathrm{M}$ electrolyte (Fig. 9). The resistance of a gel electrode filling a 1-mm-diameter capillary tube was measured with an impedance analyzer (Agilent 4294A). An 
Fig. 9 Resistance of $1 \%$ agarose gel electrode containing various electrolytes with $0.5 \mathrm{M}$ concentration (reproduced from Hattori and Yasuda 2010)

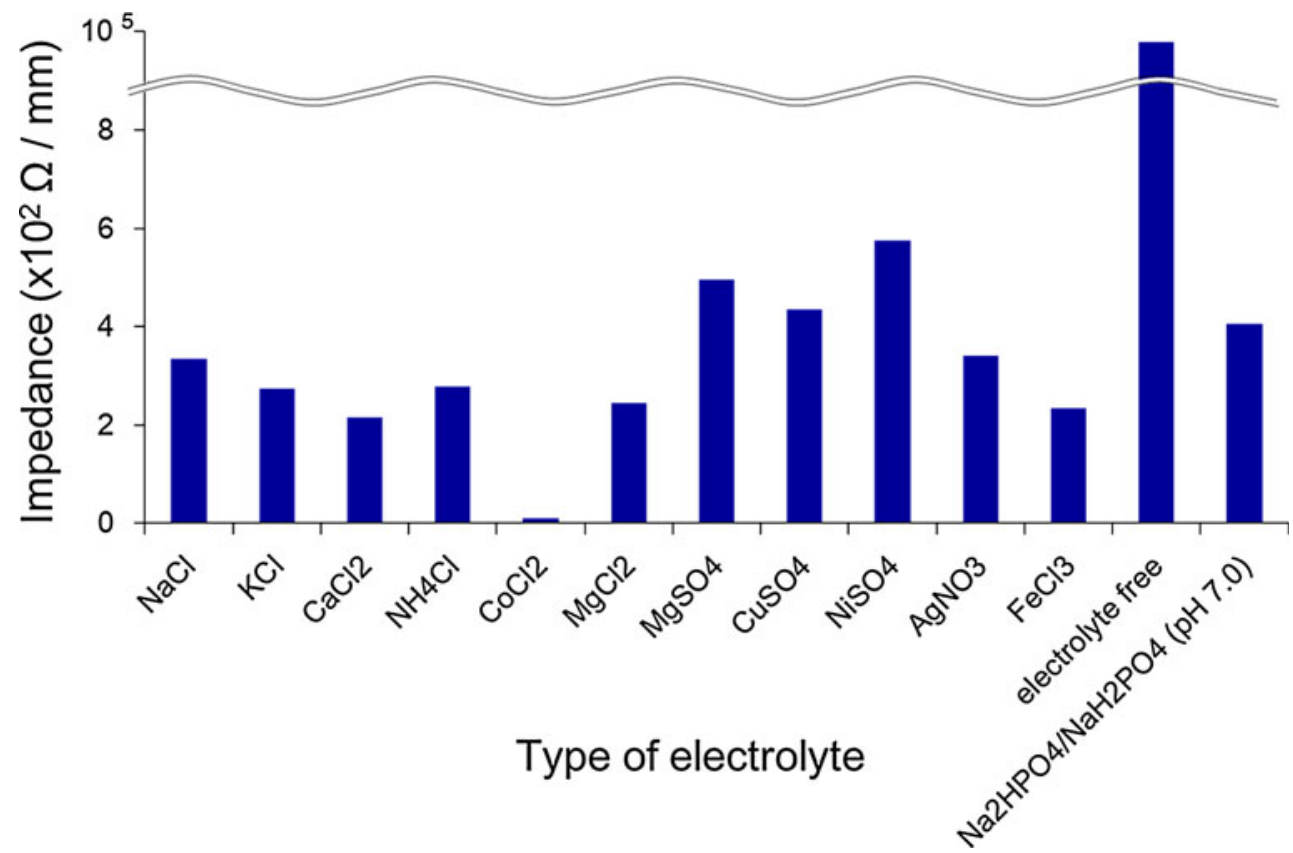

3.5 Focusing technology

\subsubsection{Hydrodynamic focusing of buffer streams in microchannel of PMMA-based cell-sorting chip for lining up samples}

To examine the efficacy of laminar flow generation in the microchannel of a PMMA-based cell-sorting chip for lining up biological samples, we loaded a solution containing red ink into the sample inlet and clear buffer into the buffer inlets (Fig. 10). The stream of sample solution was narrowed from 50 to $5 \mu \mathrm{m}$ using a hydrodynamic-focusing mechanism created by hydrodynamic-focusing inlets on both sides of the sheath stream, as described in previous reports (Takahashi et al. 2004; Sawaki et al. 2007; Hattori and Yasuda 2010; Hattori et al. 2011). The laminar flows of the sample and sheath solutions were observed without turbulence or intermixture at the flow velocity in the cellsorting area (0.1-200 mm/s; Reynolds number 0.005-10.0) (data not shown). The velocity of the microfluidic flow was measured by tracing $2-\mu \mathrm{m}$ polystyrene spheres in the laminar flow using a sequence of camera images taken at $1 / 200-1 / 10,000 \mathrm{~s}$. The flow velocity in the cell-sorting area was about ten times that in the sample inlet channel, and the linear density of the sample particles in the cell-sorting area was ten times lower than in the sample inlet channel because the ratio of the widths of the laminar flow between the sample channel and the sheath channels was 1:10 (Sawaki et al. 2007), i.e., the width of the central streamline was less than the size of a cell. The PMMA-based cellsorting chip, thus, had microchannels shaped well enough 
(a)

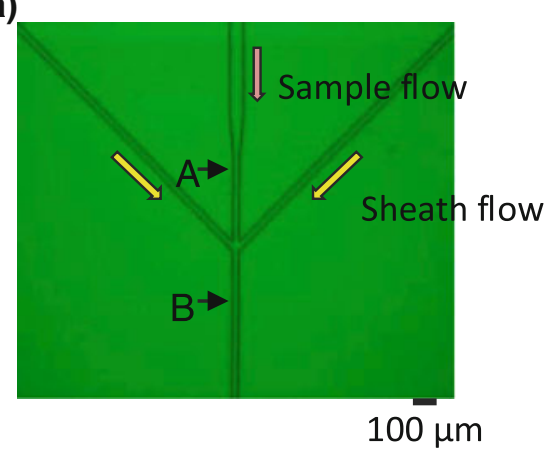

(d)

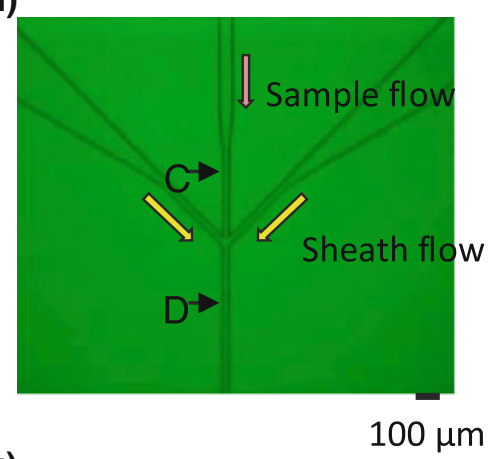

(g)

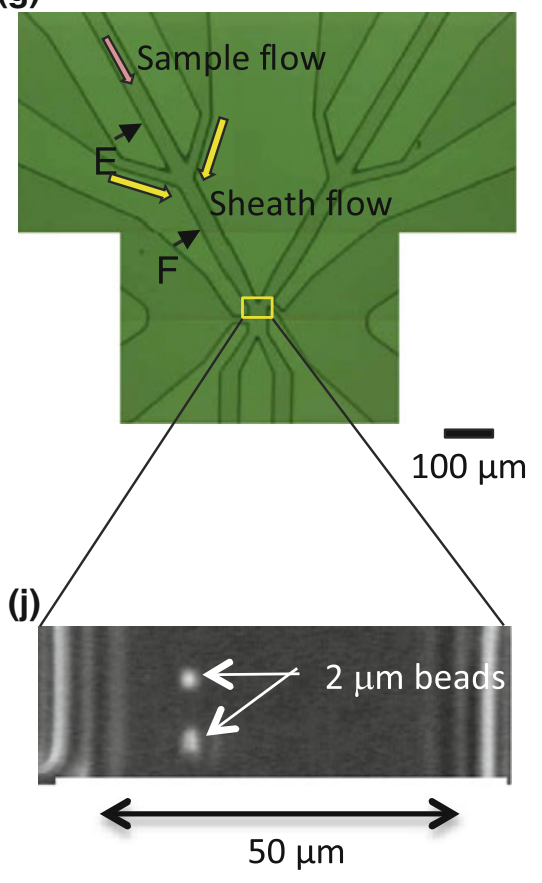

(b)

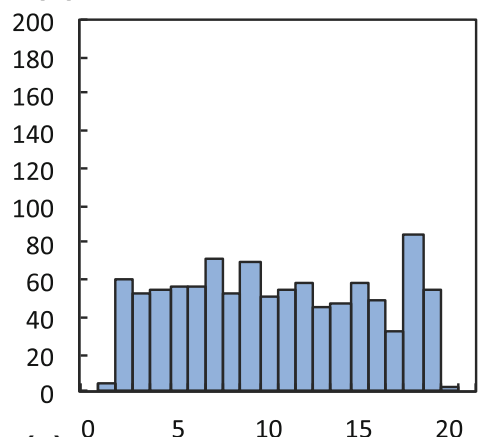

(e) 0

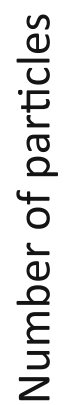

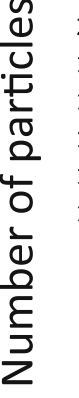

h)

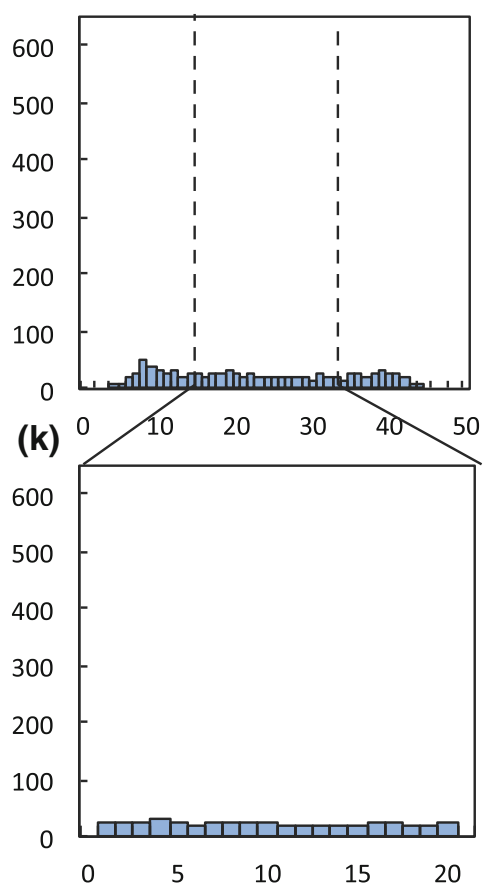

(c)
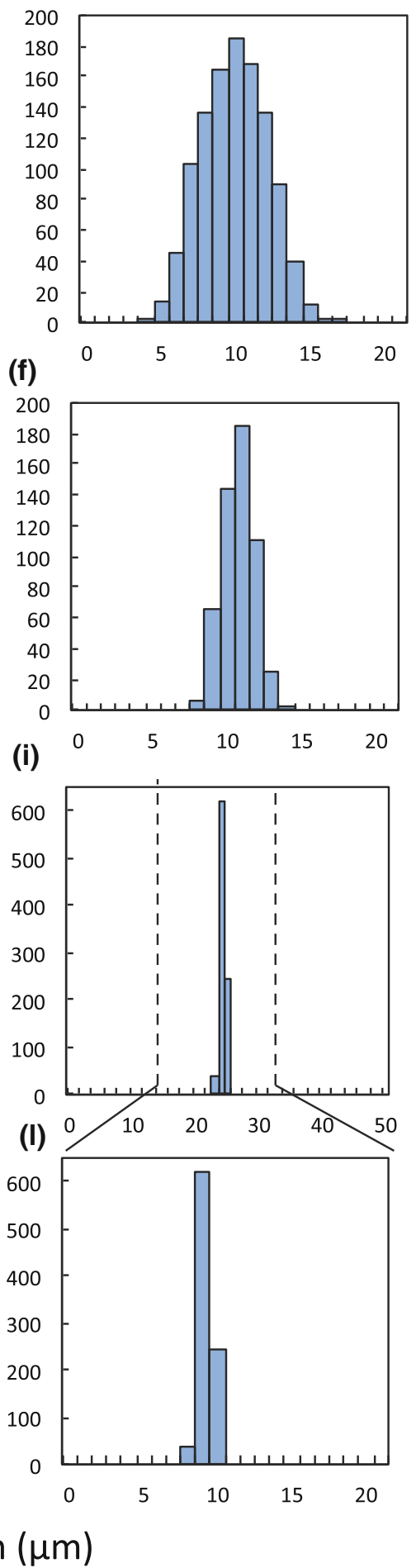

Fig. 11 Laminar flow generated by three-forked sheath structure. Sheath buffer containing red ink was used as sample solution. Flow velocity was $1 \mathrm{~mm} / \mathrm{s}$. Evaluation of shapes of two side sheath flow channels. a Micrograph of trial microfluidic chip used to evaluate effect of side sheath flows. Widths of sample channel and sheath flow channels were $20 \mu \mathrm{m}$. b Distribution of horse red blood cells in sample channel at A in a. c Distribution of red blood cells at B in a. d Micrograph of another trial microfluidic chip in which width of two side sheath flow channels changed smoothly from 200 to $20 \mu \mathrm{m}$ before reaching junction. e Distribution of red blood cells at $\mathrm{C}$ in $\mathbf{d}$. f Distribution of red blood cells at D in $\mathbf{d}$. $\mathbf{g}$ Micrograph of proposed cell-sorting chip in which width of two side sheath flow channels changed smoothly from 200 to $20 \mu \mathrm{m}$ before reaching junction. h Distribution of $2-\mu \mathrm{m}$ polystyrene beads at $\mathrm{E}$ in $\mathbf{g}$. $\mathbf{i}$ Distribution of $2-\mu \mathrm{m}$ polystyrene beads at $\mathrm{F}$ in $\mathbf{g}$. $\mathbf{j}$ Phase-contrast image of $2-\mu \mathrm{m}$ polystyrene beads in image recognition area of $\mathbf{g}$. $\mathbf{k}$ Distribution of $2-\mu \mathrm{m}$ beads for $20-\mu \mathrm{m}$ range in h. I Distribution of $2-\mu \mathrm{m}$ beads for $20-\mu \mathrm{m}$ range in i. Scale bar $100 \mu \mathrm{m}$ (reproduced from Hattori et al. 2011) 
(a)

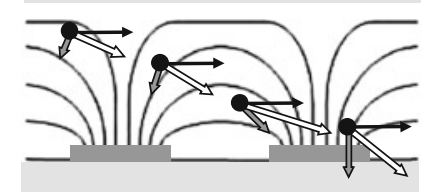

(d) (b)

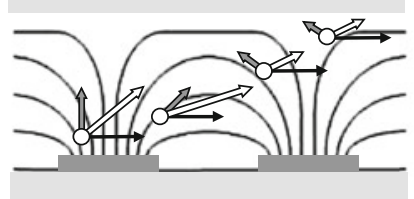

(c)

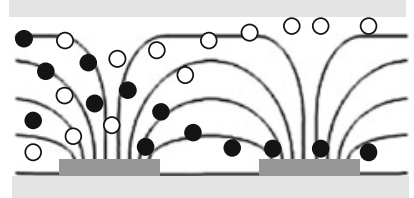

(e)

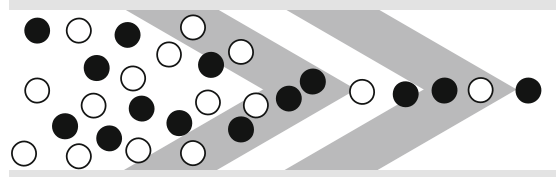

(g)

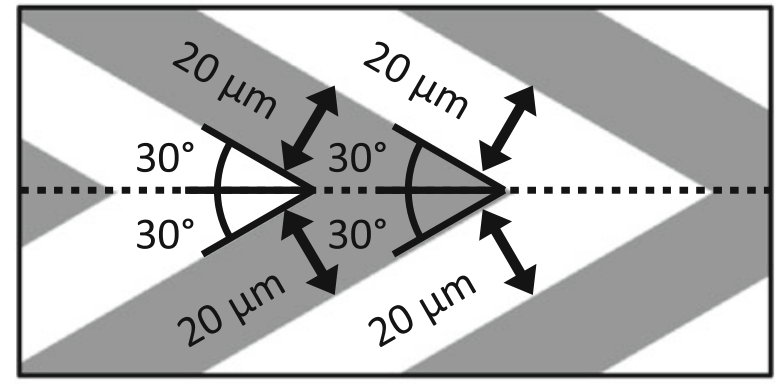

(i)

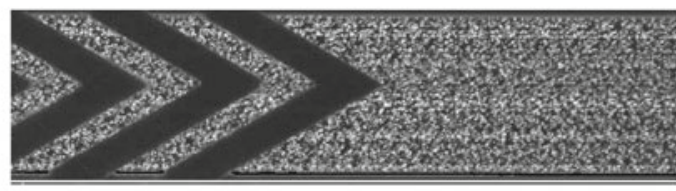

(k)

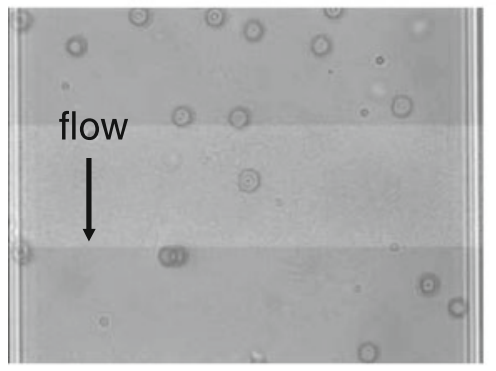

(n)

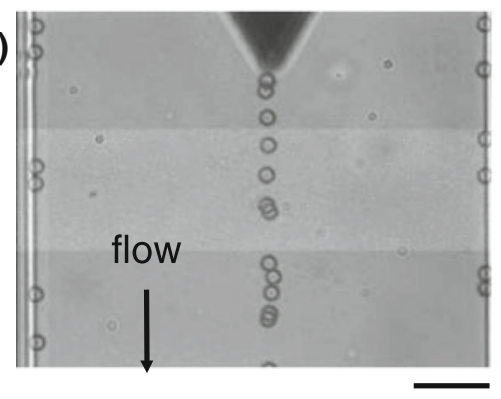

(I)

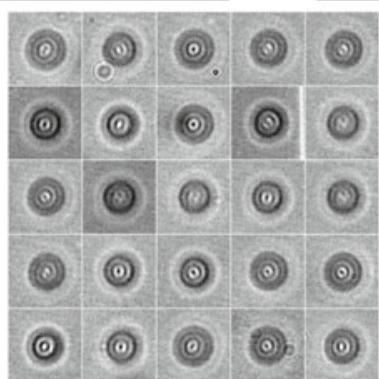

(o)

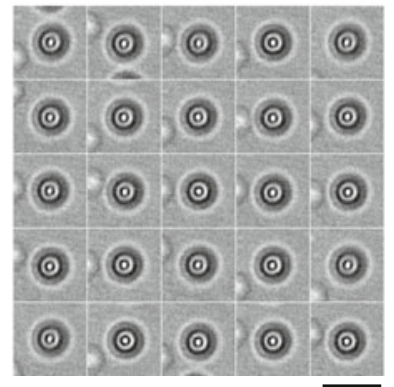

(h)

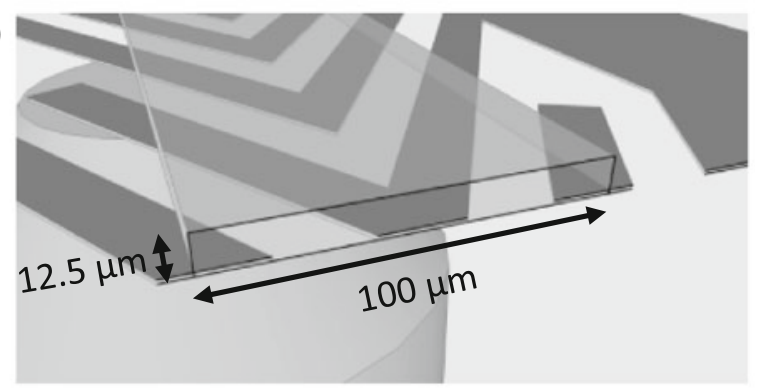

(j)

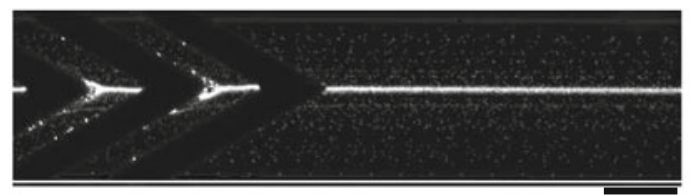

(m)

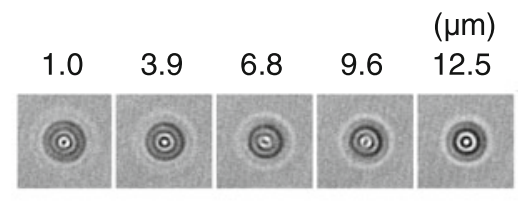

(p)

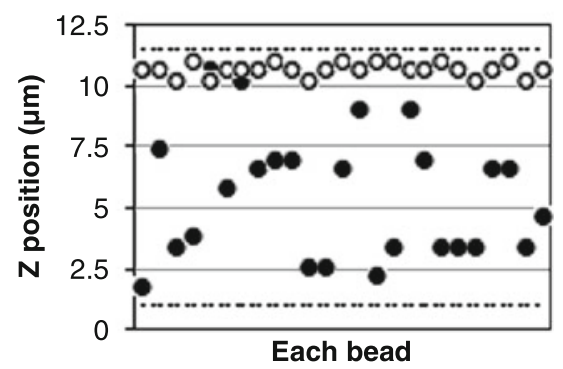


4 Fig. 12 Use of DEP force to focus microparticles. a-e Schematic images of DEP focusing. Section views $\mathbf{a}, \mathbf{b}, \mathbf{c}$ and top views $\mathbf{d}, \mathbf{e}$ of microchannel equipped with V-shaped electrode arrays (gray rectangles). Solid lines in $\mathbf{a}, \mathbf{b}$, and $\mathbf{c}$ represent electric flux lines. Direction of flow is from left to right. Circles represent microparticles with positive (black) or negative (white) DEP force applied. Arrows indicate resultant force (white arrows), fluid friction (black arrows), and DEP force (gray arrows). f-h Detail of geometry for fabricated $\mathrm{V}$-shaped electrode array. Scale bar $500 \mu \mathrm{m}$. i, j Focusing of Bacillus spores using V-shaped electrode arrays. Images when AC voltage was $\mathbf{i}$ not applied and $\mathbf{j}$ applied are shown. Scale bar $100 \mu \mathrm{m}$. k-p Experimental results for PS bead focusing using DEP force generated by a V-shaped electrode array. k, I AC voltage was not applied to electrodes; $\mathbf{n}, \mathbf{o}$ AC voltage was applied. $\mathbf{m}$ Distance of particle from bottom of microchannel was estimated by pattern matching of defocused microscopic images using standard images. Scale bar $100 \mu \mathrm{m}$ for $\mathbf{k}$ and $\mathbf{n}$ and $20 \mu \mathrm{m}$ for $\mathbf{l}, \mathbf{m}$, and $\mathbf{o}$. $\mathbf{p ~ Z}$-positions of PS beads before (filled circles) and after (open circles) flowing through $\mathrm{V}$-shaped electrode array (reproduced from Hayashi and Yasuda 2010; Hayashi et al. 2011b)

for on-chip cell sorting that was exact as that with a PDMSbased chip.

We also examined the effectiveness of hydrodynamic focusing combined with hydrodynamic-focusing side sheath inlets quantitatively. First, we examined the hydrodynamic focusing with three simple equal-flow stream lines, as shown in Fig. $11 \mathrm{a}-\mathrm{c}$, in which a $25-\mu \mathrm{m}$ sample flow stream line was confined by two $25-\mu \mathrm{m}$ flanking sheath flow lines, resulting in a combined $25-\mu \mathrm{m}$ flow line. A width of $25 \mu \mathrm{m}$ is exactly that needed to fit the width of the microfluidic pathways. Comparison of the cell distributions in the flow lines upstream (Fig. 11b) and downstream (Fig. 11c) showed that a distribution of red blood cells (diameter $5 \mu \mathrm{m}$ ) was successfully focused within a $10 \mu \mathrm{m}$ width, which is twice the sample size.

Next, we examined the contribution of accelerated hydrodynamic focusing using a wider flow line with less flow capillary resistance (Chip design B) (Fig. 11d-f). The design of the hydrodynamic-focusing inlets was changed to increase the widths of the side sheath flow channels from 25 to $200 \mu \mathrm{m}$ and focused again to $20 \mu \mathrm{m}$ immediately before focusing. We found that the distribution of cells at the center streamline was further narrowed to $5 \mu \mathrm{m}$ in the merged lower streamline (Fig. 11e-f). As this width matches the size of the target cells $(5 \mu \mathrm{m})$, the differential flow velocity of the hydrodynamic focusing is sufficiently effective to prevent particles from lining up perpendicular to the flow direction. It should be noted that we simply needed to use a single common pressure at the inlets of the center streamline and the two side streamlines to generate differential flow velocities at the hydrodynamic-focusing point because we can generate relative differences in flow velocity among streamlines using the hydrodynamicfocusing inlets. The flow velocity depends on the capillary tube's width and height. Hence, we adjusted the shape of our three-way-outlet cell-sorting chip, as shown in Fig. 4.

Finally, we applied Chip design B to our original 50- $\mu \mathrm{m}$ wide two-way-outlet cell-sorting chip (Fig. 11g-1). We used $50-\mu \mathrm{m}$ wide sample flow lines for practical application (Fig. 4). Although the width of the sample flow lines was twice that of the original chip, the width of the sample distribution after hydrodynamic focusing reached $5 \mu \mathrm{m}$ even when another sheath flow was attached to the sample flow line in the cell-sorting area (see Fig. 11j). Hence, combining two chips with design $\mathrm{B}$ did not affect each set of streamlines, meaning that multiple chips with design $\mathrm{B}$ can potentially be combined.

\subsubsection{Focusing of microparticles by dielectrophoretic force using $V$-shaped electrode array}

In addition to particle focusing using a sheath flow, another method based on dielectrophoretic (DEP) force (Hayashi and Yasuda 2010; Hayashi et al. 2011b) was also examined. The DEP force, $F_{\mathrm{DEP}}$, acting on a particle in a nonuniform electric field is given by the following equations (Hughes 2002):

$F_{\mathrm{DEP}}=\left(\pi D^{3} \varepsilon_{\mathrm{m}} \operatorname{Re}\left[f_{\mathrm{CM}}\right] \nabla E^{2}\right) / 4$,

$f_{\mathrm{CM}}=\left(\varepsilon_{\mathrm{p}}^{*}-\varepsilon_{\mathrm{m}}^{*}\right) /\left(\varepsilon_{\mathrm{p}}^{*}+2 \varepsilon_{\mathrm{m}}^{*}\right)$

where $D$ is the particle diameter, $\varepsilon_{\mathrm{m}}$ is the permittivity of the medium, $f_{\mathrm{CM}}$ is the Clausius-Mossotti (CM) factor, $E$ is the applied electric field, and $\varepsilon_{\mathrm{m}}^{*}$ and $\varepsilon_{\mathrm{p}}^{*}$ are the complex permittivities of the medium and the particle, respectively. The complex permittivity is defined as

$\varepsilon^{*}=\varepsilon-(i \sigma) / \omega$,

where $\varepsilon$ is the electric permittivity, $\sigma$ is the electric conductivity, and $\omega$ is the angular frequency of the applied

Table 1 Comparison of two focusing methods investigated

\begin{tabular}{llllll}
\hline Focusing method & $\begin{array}{l}\text { Durability for } \\
\text { long-term measurement }\end{array}$ & $\begin{array}{l}\text { Capability for } \\
\text { high-flow velocity }\end{array}$ & $\begin{array}{l}\text { Anti-dilution } \\
\text { of samples }\end{array}$ & $\begin{array}{l}\text { Ability of } \\
\text { concentration }\end{array}$ & $\begin{array}{l}\text { Control of } \\
\text { flow velocity }\end{array}$ \\
\hline Sheath flow focusing & 0 & 0 & $\times$ & $\times$ & $\times$ \\
DEP focusing & 0 & $\times$ & $\bigcirc$ & 0 & 0 \\
\hline
\end{tabular}

$\bigcirc$ suitable, $\times$ unsuitable 
Fig. 13 Particle separation using two- and three-way outlet cell-sorter chips. Switching mechanism using electrophoresis of gel electrodes: a, b two-way type and $\mathbf{d}-\mathbf{g}$ three-way type chip. c Color codes for charge state of sample particles and buffers. a, d Without DC voltage application, sample particles flowed along path marked by red line. $\mathbf{b}, \mathbf{e}, \mathbf{f}$ Application of DC voltage switched the outlet channel depending on particle's charge and DC voltage polarity. g Mixed particles with negative, positive, or no charge were sorted correctly. Tracks of $20-\mu \mathrm{m}$ polystyrene particle on two-way outlet chip $\mathbf{h}$ without and $\mathbf{i}$ with DC voltage applied between gel electrodes.

Separation of $2-\mu \mathrm{m}$ polystyrene particles (green track) and fluorescein (red track) $\mathbf{j}$ without and $\mathbf{k}$ with DC voltage applied between gel electrodes. Dependence of sorting efficiency on I DC voltage between gel electrodes and m flow velocity. Tracks of a $2-\mu \mathrm{m}$ polystyrene particle on three-way outlet chip $\mathbf{n}$ without and $\mathbf{o}, \mathbf{p}$ with DC voltage applied in opposite directions between gel electrodes.

Direction of electric field is indicated by plus and minus icons. Flow direction in all figures was from top to bottom (reproduced from Hayashi et al. 2011a) (a)

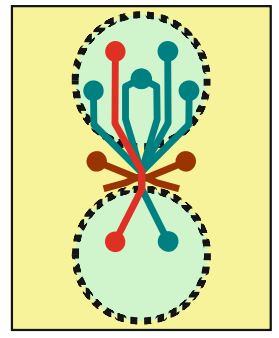

(d)

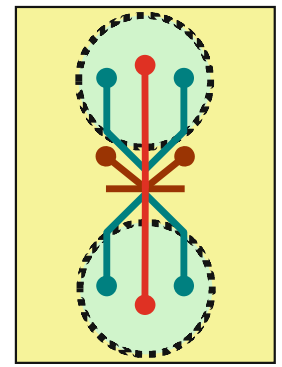

(h)

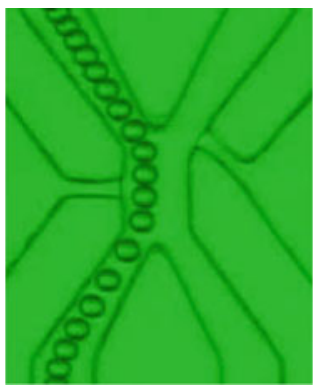

(I) (b)

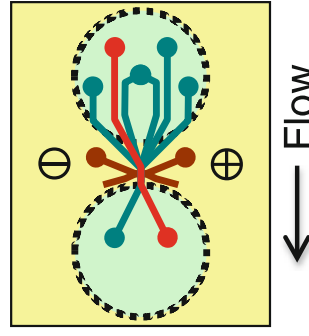

(e)

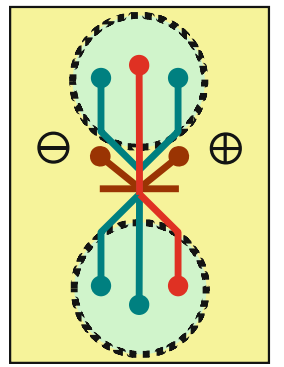

(i)

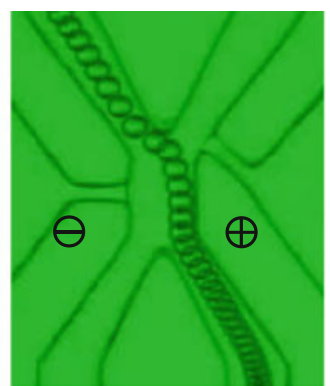

$50 \mu \mathrm{m}$

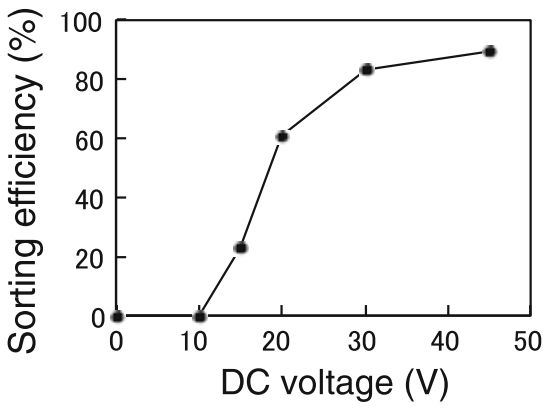

(n)

(o) (c)

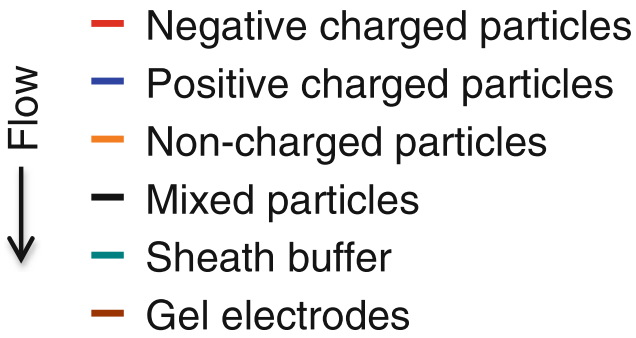

(f)

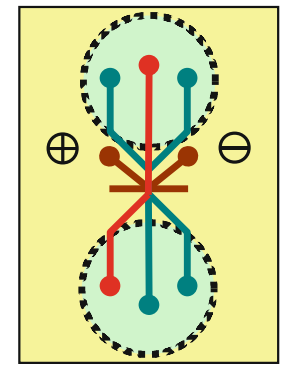

(j)

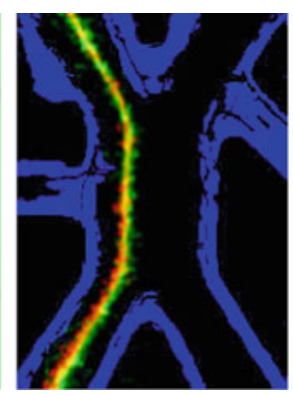

(m) (g)

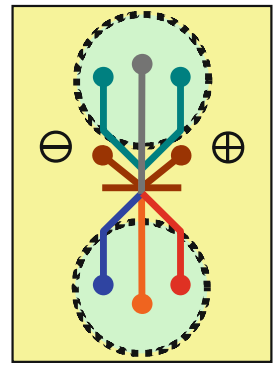

(k)

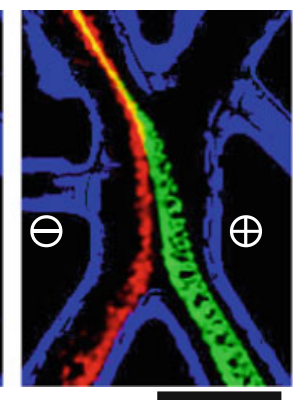

$50 \mu \mathrm{m}$
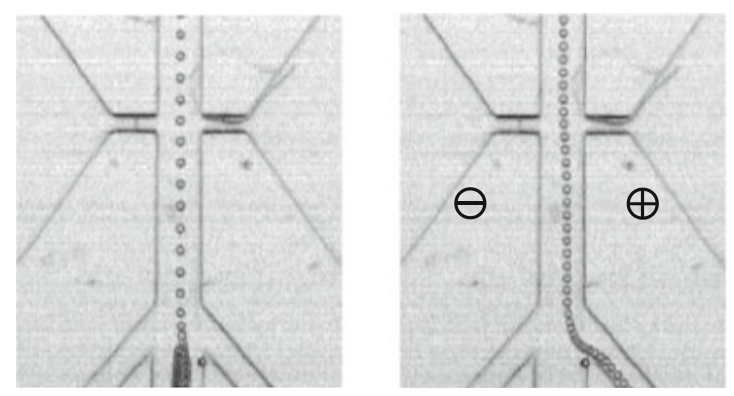

(p)

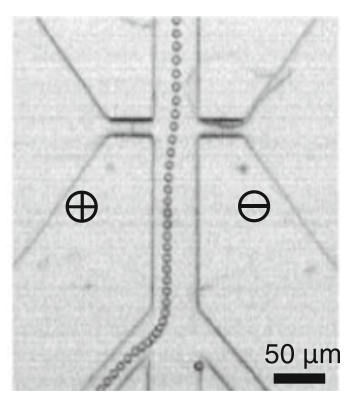


electric field. When the real part of the CM factor is positive, a particle moves toward stronger electric fields, and when the real part is negative, it moves toward weaker ones.

To focus microparticles including cells toward the center of a microfluidic channel using the DEP force, a $\mathrm{V}$-shaped electrode array was placed at the center of the microchannel, as shown in Fig. 12 (Hayashi and Yasuda 2010; Hayashi et al. 2011b). An electrode array was placed on the bottom of the microfluidic channel, and alternate electrodes were connected to the opposite terminals of an alternating current (AC) power supply. The principle of particle focusing is as follows. Application of a voltage causes a non-uniform electric field to form. The strongest region is at the edge of the electrodes at the bottom of the channel, and the weakest region is at the top, immediately above the electrodes. If the DEP force (gray arrows in

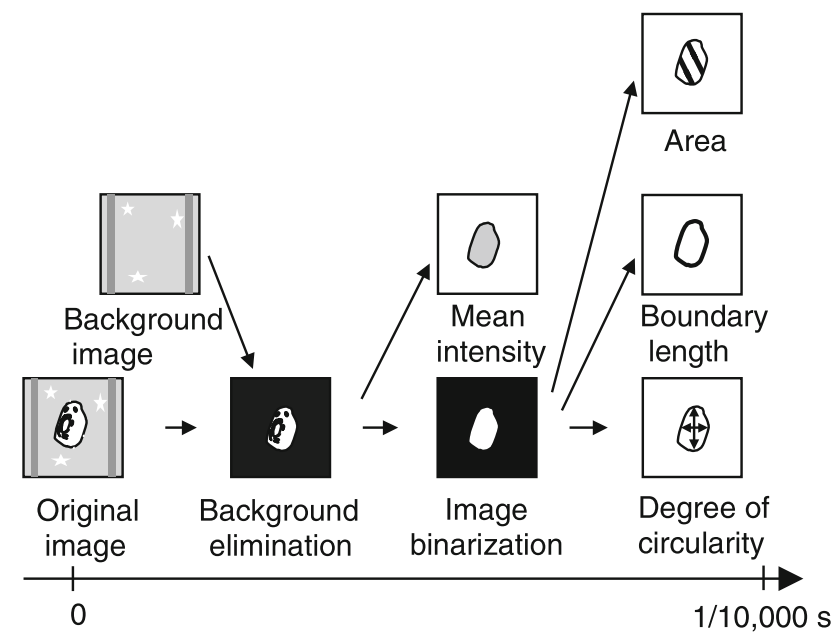

Fig. 14 Analysis of microscopic image in real time using imageprocessing unit for $1 / 10,000$-s interval
Fig. 15 Real-time sizediscrimination of polystyrene particles close in size $(2.5$ or $3.0 \mu \mathrm{m}$ in diameter) using microscopic images bright-field microscopic images of particles with diameter of $\mathbf{a} 2.5 \mu \mathrm{m}$ or b $3.0 \mu \mathrm{m}$. Histograms of particle areas measured with imaging cytometry system at flow velocity of $10 \mathrm{~mm} / \mathrm{s}$ : sample suspension containing c only $2.5-\mu \mathrm{m}$ particles, $\mathbf{d}$ only 3.0- $\mu \mathrm{m}$ particles, and e mixed suspension with 2.5 - and $3.0-\mu \mathrm{m}$ particles (reproduced from Hayashi et al. 2011a) (a)

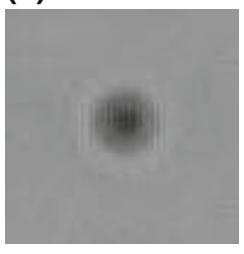

(b)
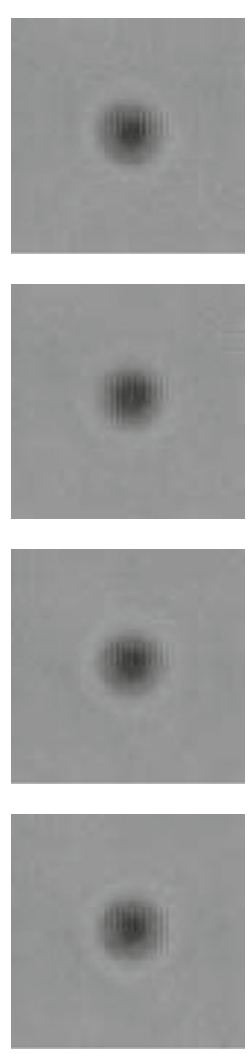
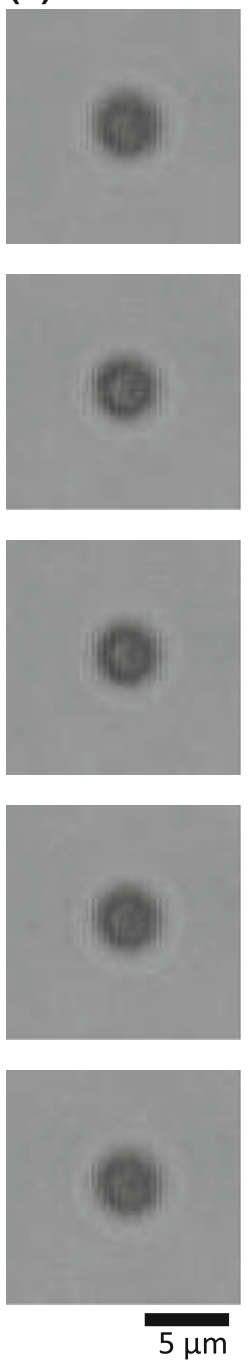
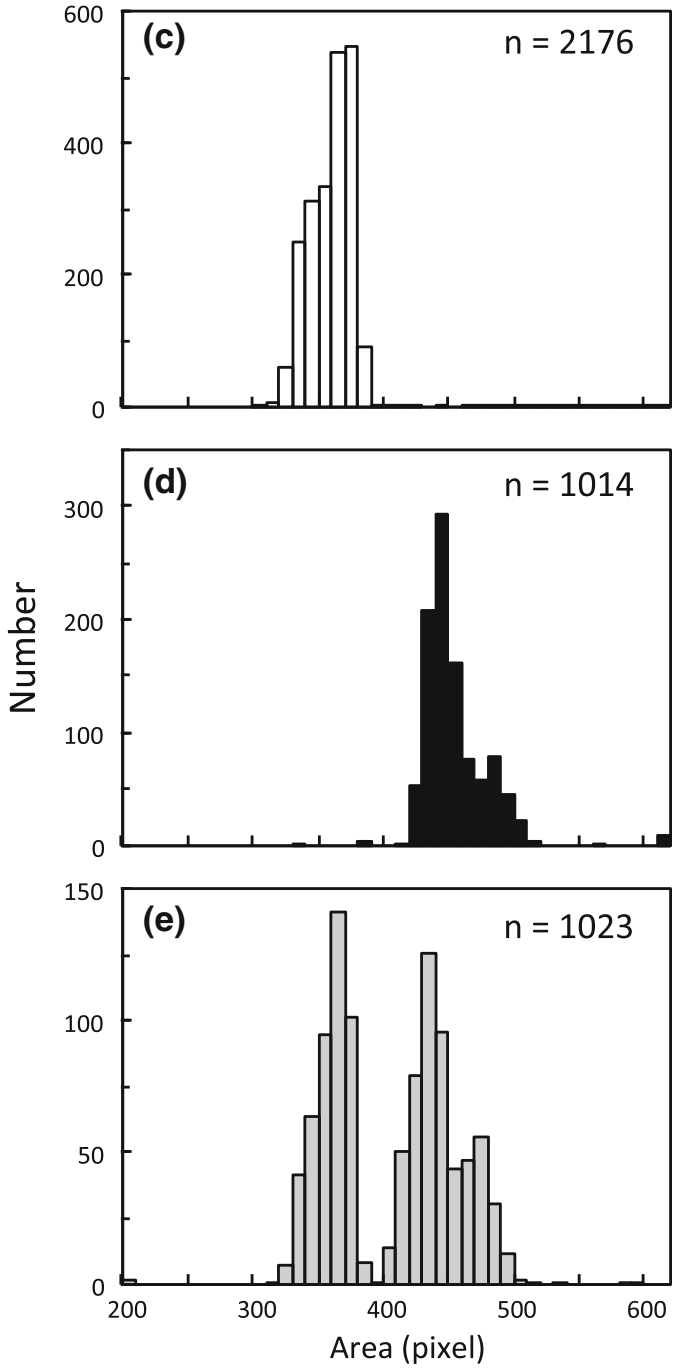
Fig. 16 Extended depth of field optics for precise image analysis in microfluidic imaging flow cytometry. Micrographs of $15-\mu \mathrm{m}$ polystyrene bead acquired by zoom optics (upper) and inverted microscope (lower) for every $5-\mu \mathrm{m}$ depth at total magnifications of a $10 \times$, b $20 \times$, and c $40 \times$ (reproduced from Hattori and Yasuda 2012) (a)

$10 \mathrm{x}$
$(10 \mathrm{x}+1 \mathrm{x}$ zoom, NA $=0.28)$
$10 \mathrm{x}$
$(\mathrm{NA}=0.3)$

\section{(b)}

$(10 x+2 x$ zoom, NA $=0.28)$
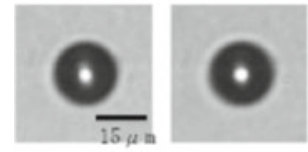

$20 x$

$(\mathrm{NA}=0.4)$
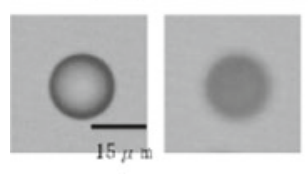

(c)

$40 x$
$(10 x+4 x$ zoom, $N A=0.28)$

$40 x$

$(\mathrm{NA}=0.6)$
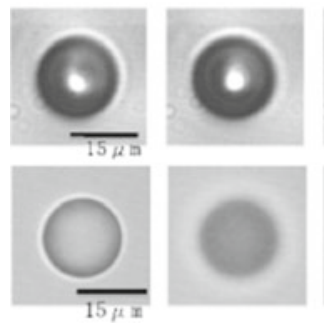
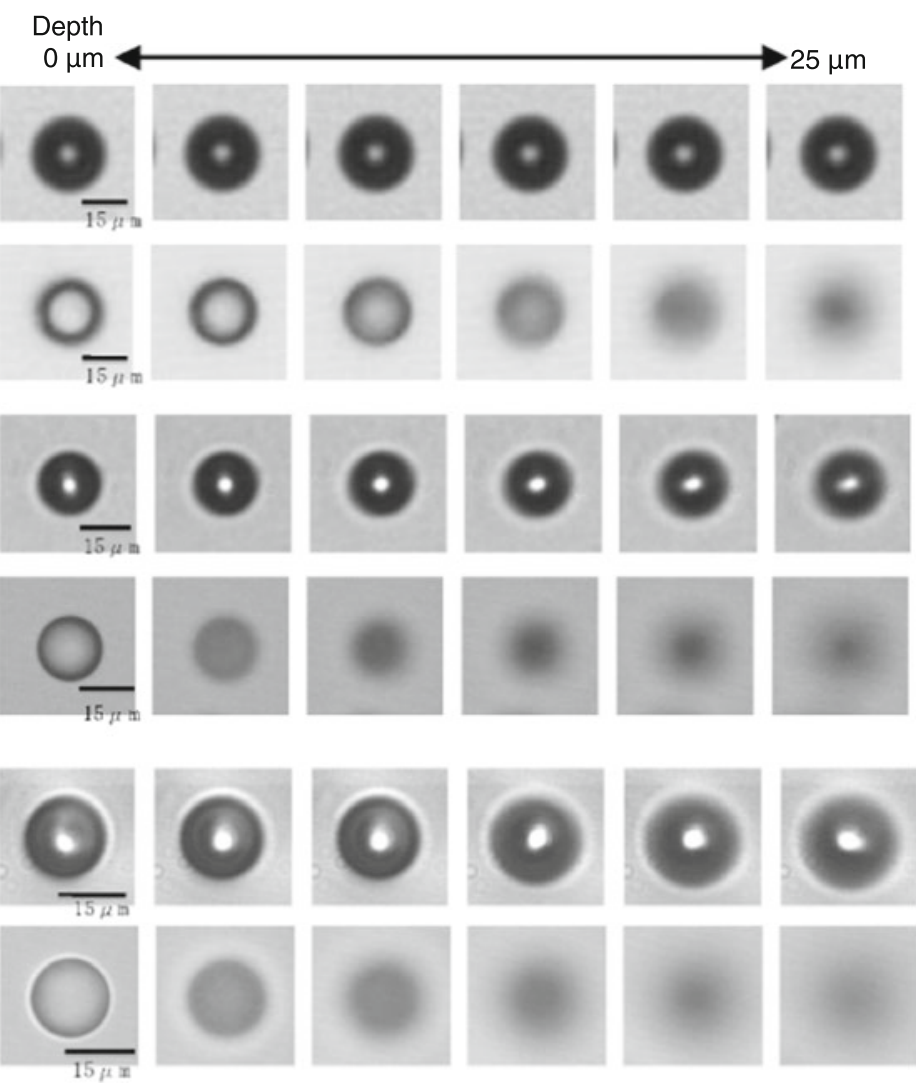

Fig. 12a) on a particle is positive, the particle is pulled toward one edge of the electrodes. In total of forces between DEP and fluid friction, the particle moves in the tip end direction of the electrode in horizontal and bottom in vertical. If the DEP force on a particle is negative (Fig. 12b), the particle moves in the tip end direction in horizontal and top in vertical in the same manner as with a positive charge. In short, all particles are aligned in the tipend direction of the $\mathrm{V}$-shaped electrode in the horizontal direction (Fig. 12e) and also focused toward the bottom (positive DEP) or the top (negative DEP) of the microchannel in the vertical direction (Fig. 12c). The sign of the DEP force depends on the real part of the CM factor, as shown in Eq. (1), and it generally depends on the particle type and AC frequency. These properties have been well studied, enabling the DEP force to be used for concentrating and separating particles, including cells (Urdaneta and Smela 2007; Huang et al. 2011; Unni et al. 2012; Wu et al. 2012).

The focusing ability of a method based on the DEP force was tested using Bacillus spores (about $1 \mu \mathrm{m}$ in diameter) as a cell model with the application of $20 \mathrm{~V}_{\mathrm{pp}}$ and $1 \mathrm{MHz}$ of AC voltage (Hayashi and Yasuda 2010; Hayashi et al. 2011b). The spores flowed in the microchannel at a velocity of $1 \mathrm{~mm} / \mathrm{s}$. They moved across the stream along the lines of the V-shaped electrode array from the periphery to the center of the microchannel, as shown in Fig. 12j.
For the vertical direction, the focusing position of the spores was at the bottom of the microchannel because the spores were subjected to positive DEP forces under the experimental conditions. The vertical distribution of particles was measured using polystyrene (PS) beads $(1 \mu \mathrm{m}$ in diameter) under the same electric field conditions as that for the Bacillus spores (Hayashi and Yasuda 2010). The distribution was measured by pattern matching of their defocused microscopic images (Fig. 12k-p). The CM factor of the PS beads was negative (i.e., negative DEP); Fig. $12 p$ shows that randomly distributed PS beads (filled circles) were concentrated on the ceiling of the microchannel (open circles).

As described above, we tested two focusing methods: sheath flow focusing and DEP force focusing. Both methods have advantages and disadvantages, as summarized in Table 1. Sheath flow focusing is suitable for high-flow velocity because a stable laminar flow forms even when the flow velocity is quite fast. DEP focusing is suitable for small amount of samples without dilution of sample buffer concentration. The flow velocity is easier to control with DEP focusing, because DEP focusing do not request any balance control of flow velocities of additional side sheath buffers. However, the suitability of DEP focusing for highflow velocity is, in principle, limited because of the electrolysis of the solvents used for application of AC voltage to the electrodes placed only on the bottom of the 
(a)

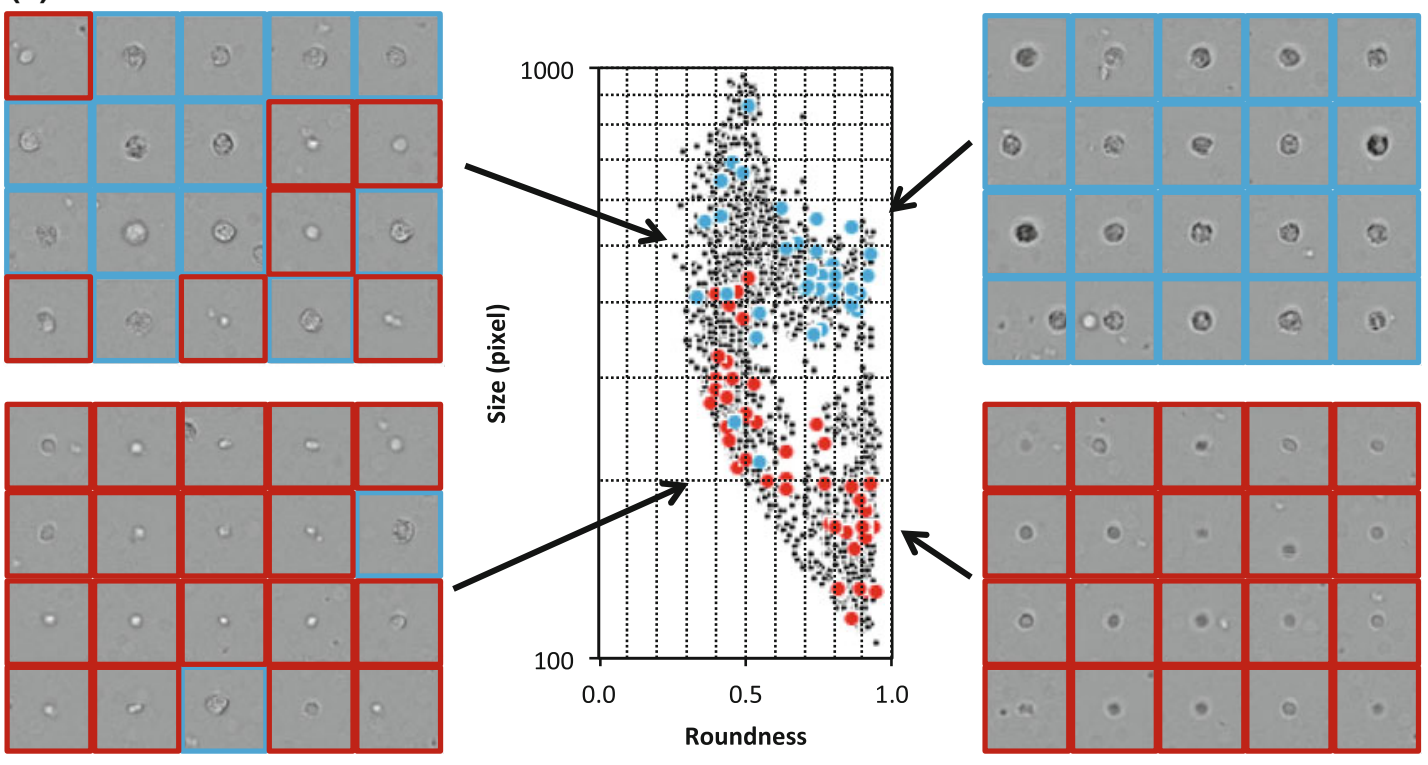

(b)

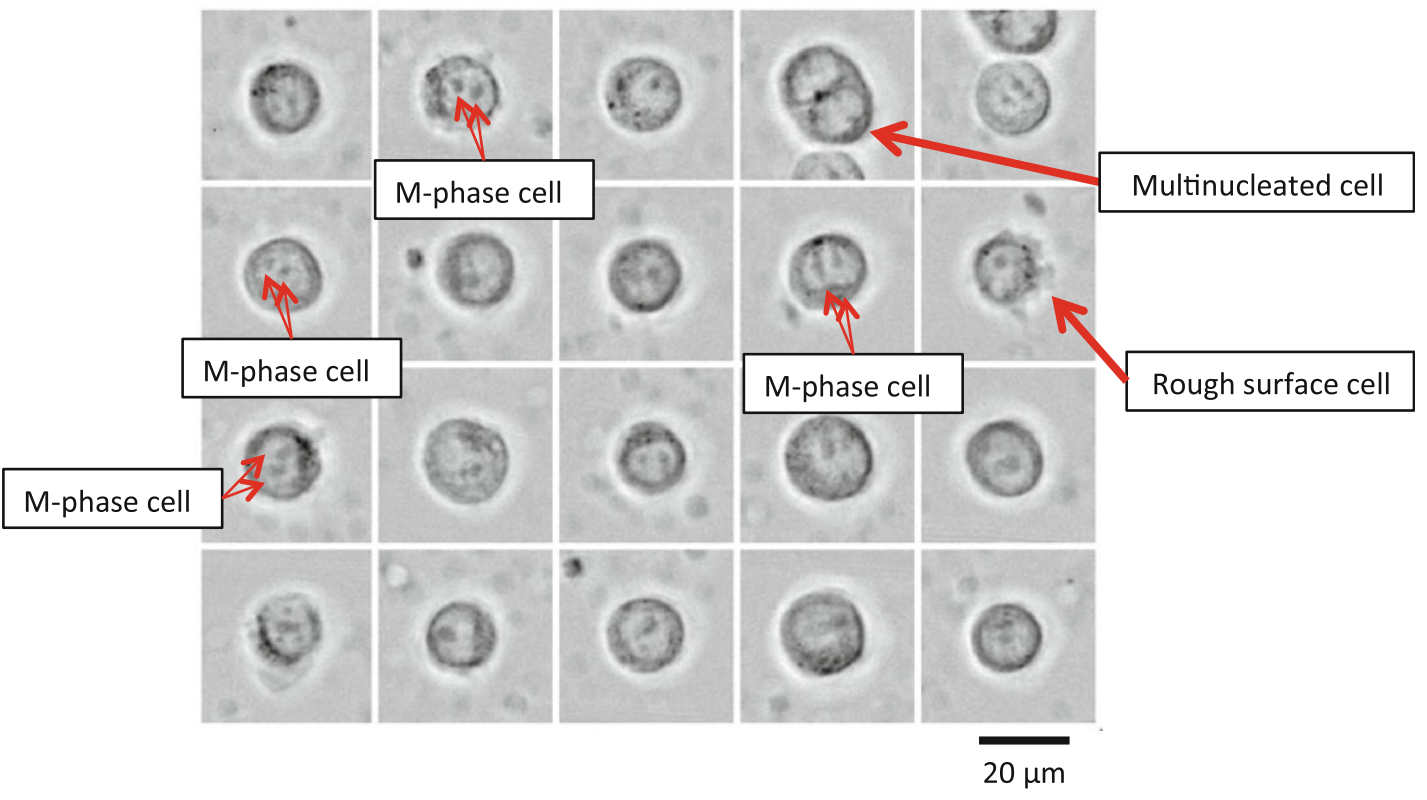

Fig. 17 Two-dimensional mapping of acquired cell images. a Analyzed roundness and size (cross-sectional area) of each cell image is plotted on map at center. Original images were stored and cross

microfluidic channel. Taking these points into account, we are using sheath flow focusing for our high-speed cellsorting system until the problems with V-shaped DEP focusing are solved.

\subsection{Particle sorting and separation using \\ two- and three-way-outlet cell-sorting chips}

We fabricated both types of PMMA-based cell-sorting chips described above. The sample particles were aligned on the centerline of an upstream microchannel using the referenced to plots. b Magnified micrographs of acquired cell images. Even at a rate of 10,000 images/s, the resolution was good enough to identify M-phase cells, multinucleated cells, and rough surface cells

sheath flow mechanism, and they passed through the cellsorting area between the gel electrodes. The outlet channel was switched using electrophoresis by switching the DC voltage applied to the electrodes, while particles were passing between the tips of gel electrodes.

With the two-way-outlet chip, the inlet channels had a symmetrical structure (Figs. 4a-c, 13a-b). The sample inlet flow was sheathed by two sheath channels. The sheathed channels and their mirror-image-like channels joined at the gel electrode connection point and branched into two symmetrical outlet channels. When the DC 


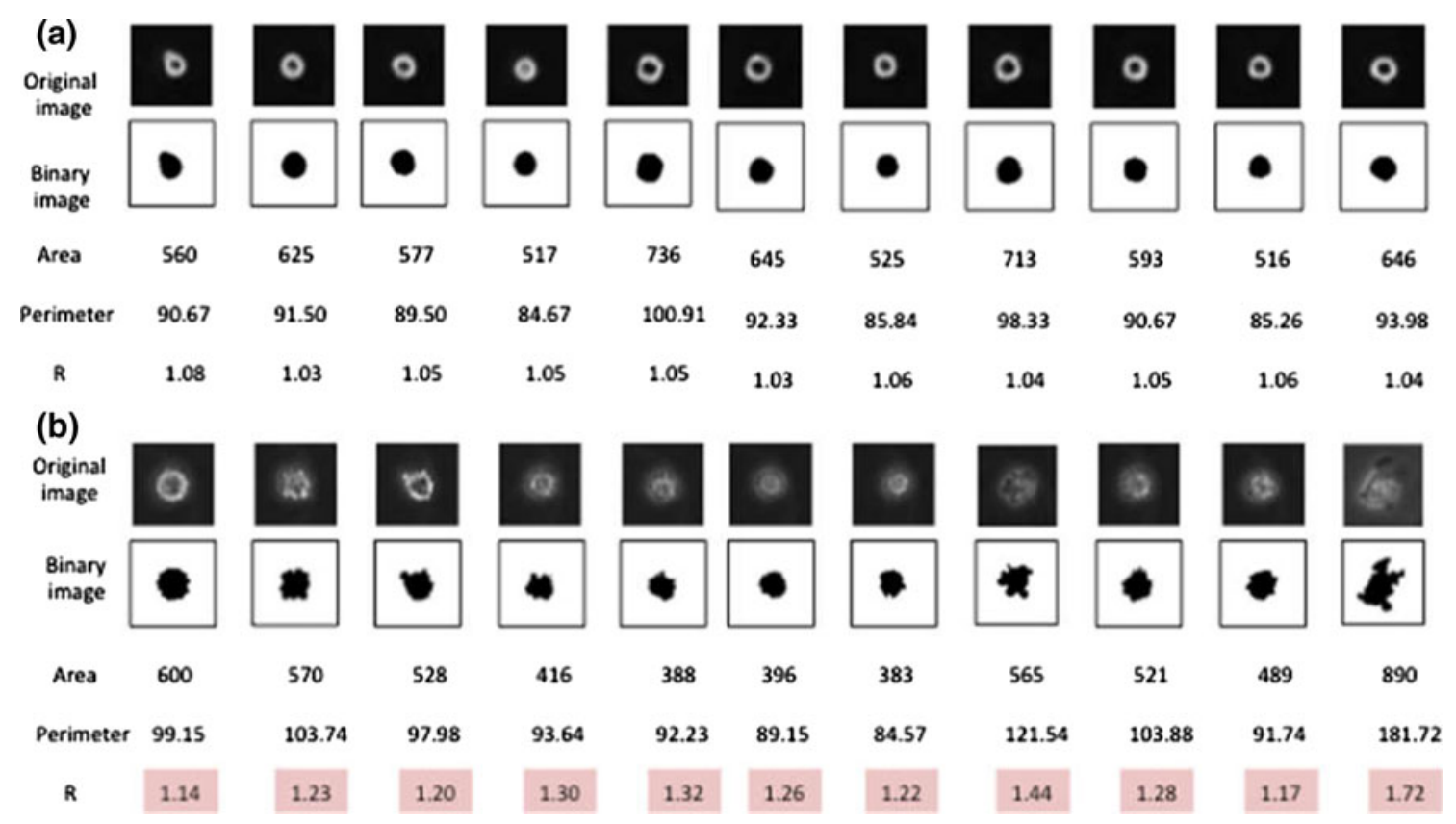

Fig. 18 Separation of cardiomyocyte cells using on-chip imaging flow cytometry system. Phase-contrast images and field programmable gate array (FPGA) calculated indexes of $\mathbf{a}$ target smooth cells (cardiomyocytes) and $\mathbf{b}$ non-cardiomyocyte cells (reproduced from Nomura et al. 2011)

Table 2 Results of separating cardiomyocyte cells

\begin{tabular}{|c|c|c|c|c|c|c|c|}
\hline & \multirow{2}{*}{$\begin{array}{l}0 \text { DIV } \\
\text { Smooth cells }\end{array}$} & \multicolumn{4}{|l|}{2 DIV } & \multicolumn{2}{|c|}{ Cardiac myosin staining } \\
\hline & & Beating cells & Non-beating cells & Shrunk cells & Unattached cells & Positive cells & Negative cells \\
\hline Number & 242 & 178 & 19 & 12 & 33 & 195 & 2 \\
\hline Ratio (\%) & 100 & 73.6 & 7.9 & 5 & 13.6 & 80.6 & 0.8 \\
\hline
\end{tabular}

Table 3 Seven candidate commercial membrane filters for use as isolation filter

\begin{tabular}{|c|c|c|c|c|c|c|c|}
\hline Criteria & Omnipore & Express & Nylon & Isopore & Durapore & Fluoropore & PVC \\
\hline Thermal resistance & $\times$ & $\bigcirc$ & $\bigcirc$ & $\bigcirc$ & $\bigcirc$ & $\times$ & $\times$ \\
\hline Ruck-free & $\bigcirc$ & $\bigcirc$ & $\bigcirc$ & $\times$ & $\bigcirc$ & $x$ & $\times$ \\
\hline Hydrophilia & $\bigcirc$ & $\bigcirc$ & $\bigcirc$ & $\times$ & $\times$ & $\times$ & $\times$ \\
\hline Transparency & 0 & $x$ & $\times$ & $\times$ & $\times$ & $\times$ & $\times$ \\
\hline
\end{tabular}

$\bigcirc$ meets requirement, $x$ does not meet requirement

voltage between the gel electrodes was turned off, the stream of sample particles exited the same side outlet (Fig. 13a); when the DC voltage was turned on, it exited the other outlet (Fig. 13b). The separation efficiency with a two-way-outlet cell-sorting chip when a DC voltage was continuously applied depended on the voltage and flow velocity (Fig. 131-m). At a constant flow velocity, the separation frequency increased with the DC voltage and reached a plateau: the efficiency was $90 \%$ at $45 \mathrm{~V}$ for a flow velocity of $200 \mathrm{~mm} / \mathrm{s}$ (Fig. 131). On the other hand, at a constant voltage, the separation frequency decreased as the flow velocity was increased, and eventually no particles were separated; the efficiency was less than $50 \%$ at $45 \mathrm{~V}$ for a flow velocity of $500 \mathrm{~mm} / \mathrm{s}$ (Fig. 13m). Moreover, the two-way-outlet chip did not separate the small molecules and charged particles; rather it moved the charged particles away from the small molecules, i.e., the polystyrene particles and fluorescein in the sample mixture were completely separated (Figs. 13j-k).

With the three-way-outlet chip, there were two sets of sheathed triplet channels symmetrically arranged as inlet and outlet channels on the chip (Figs. $4 \mathrm{~d}-\mathrm{f}, 13 \mathrm{~d}-\mathrm{g}$ ). When the DC voltage between the gel electrodes was turned off (Fig. 13d, n), the stream of sample particles exited the center outlet; when the DC voltage was turned on, each particle exited one of the other outlets depending on the 
(a)

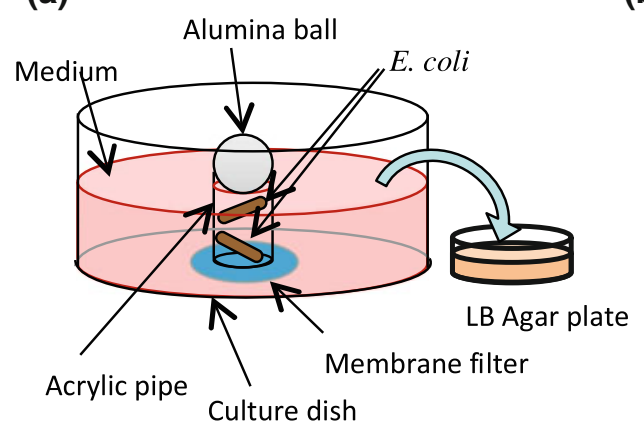

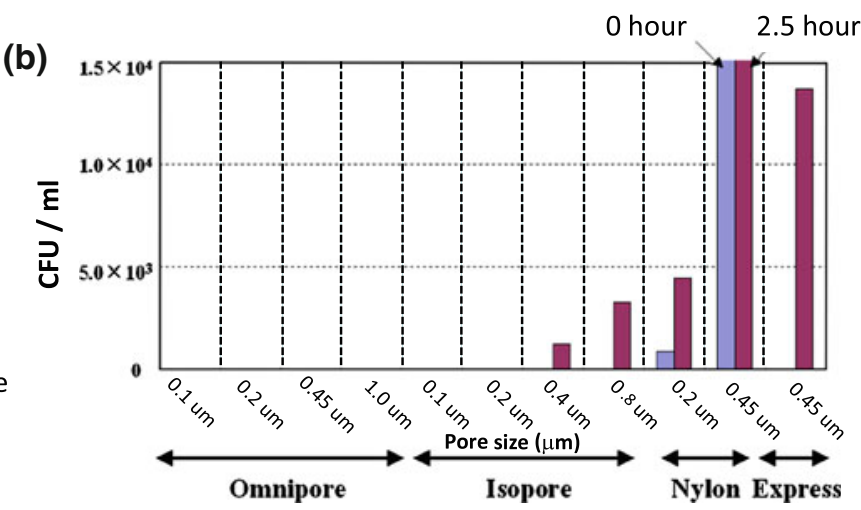

Fig. 19 Permeability of membrane filters to E. coli: a experimental setup, b number of colonies on lysogeny broth (LB) agar plate after removal from medium following injection of $E$. coli suspension into dummy outlet tube (reproduced from Hayashi et al. 2011a)

(a)

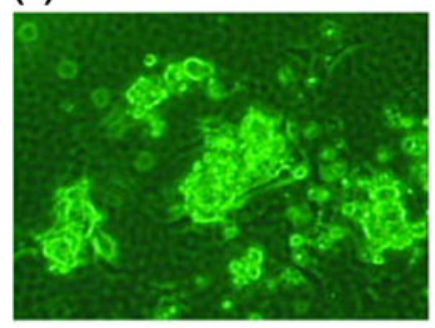

(d)

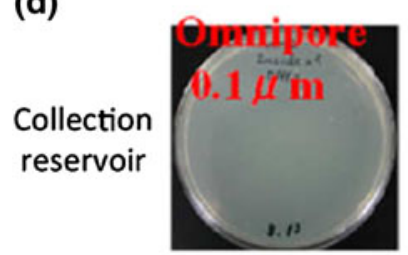

(g)

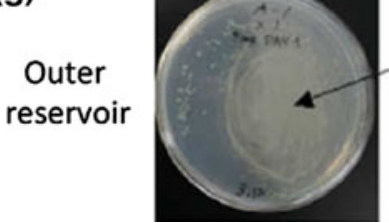

(b)

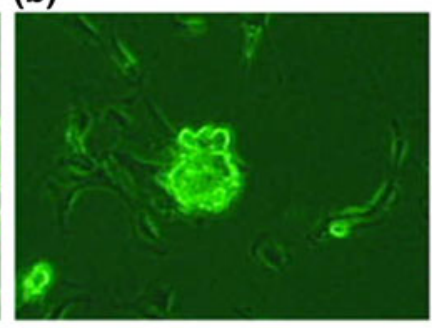

(e)

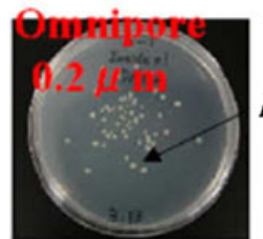

(h)

E. coli

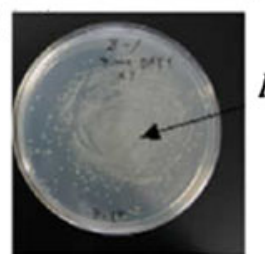

(c)

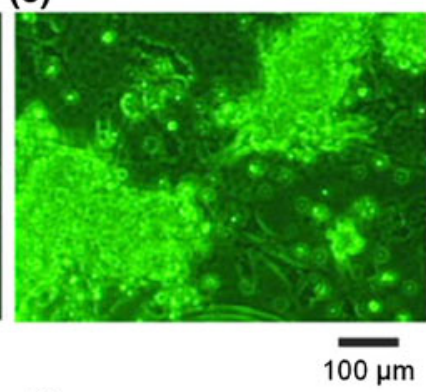

(f)

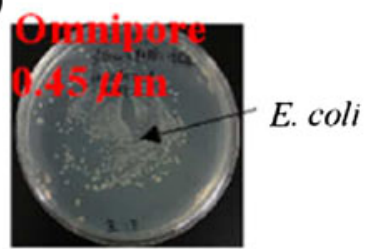

(i)

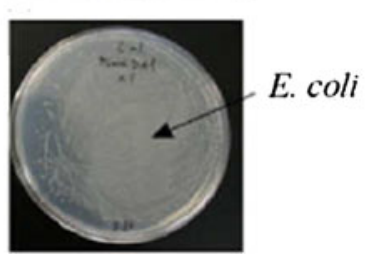

Fig. 20 Estimation of cell viability and contamination from downstream reservoir. a-c Cardiomyocyte cells at bottom of outlet tube after cultivation for 2 days. Most cells were beating. LB agar plate exposed to medium in $\mathbf{d}-\mathbf{f}$ collection reservoir and $\mathbf{g}-\mathbf{i}$ outer

particle's charge and the direction of the applied DC electrical field (Fig. 13e-f, o-p). The particles in a mixed suspension containing negatively charged, positively charged, and non-charged particles were separated into the three outlet channels depending on the charge state of each particle (Fig. 13g). This means that the three-way chip can be used for purification of target cells from a crude sample mixture containing various kinds of undesired particles such as non-target cells, debris, and inanimate particles. reservoir after cultivation for 2 days. Cultivation chip outlet tubes were sealed with Omnipore filter with pore size of $0.1 \mu \mathrm{m}(\mathbf{a}, \mathbf{d}, \mathbf{g})$, $0.2 \mu \mathrm{m}(\mathbf{b}, \mathbf{e}, \mathbf{h})$, or $0.45 \mu \mathrm{m}(\mathbf{c}, \mathbf{f}, \mathbf{i})$ (reproduced from Hayashi et al. 2011a)

\section{Image analysis}

\subsection{Real-time recognition of image of flowing particles}

The image-processing unit recognized the image of each flowing particle at a rate of up to 10,000 frames/s and 1/200- to 1/10,000-s analysis intervals, as shown in Fig. 14. A background image of the observation area was acquired at the end of the initialization process. To determine the boundary of a particle image during the sorting process, the 
Fig. 21 Integrated system: a schematic drawing and b photograph. Ultra-high-speed droplet PCR module is located at bottom; immediately above it is on-chip imaging flow cell-sorting module. Sample preparation module (c) is at top; in it, the particulate solution is forced through a dyeing/ concentration nozzle (d). Particulates are concentrated by membrane filter attached to bottom of filter housing

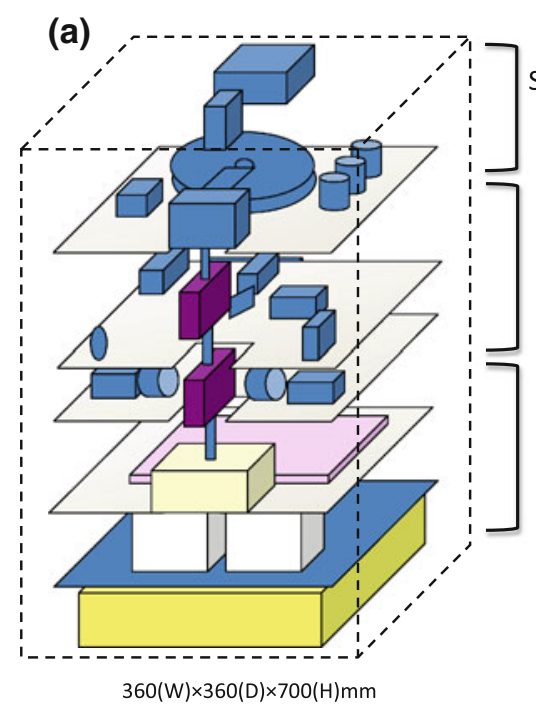

(b)

Sample preparation

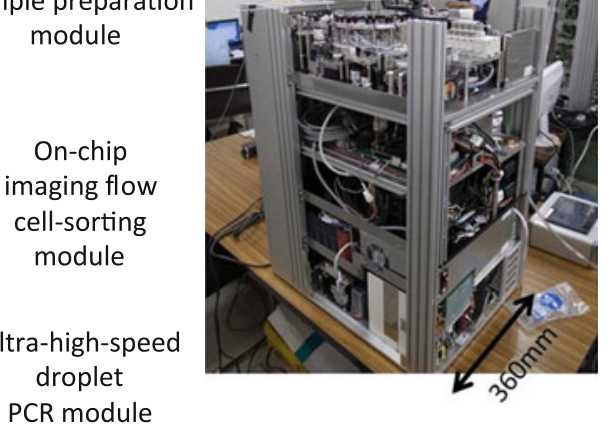

PCR module

(c)

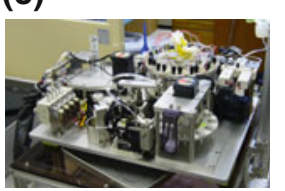

background image was subtracted from the original image in each frame, and the resulting image was binarized using a preset threshold. The parameters of a particle's image, the mean intensity, area, lengths of major and minor axes, degree of circularity, etc., were calculated about the pixel value within the boundary. When one of, or a set of, the parameters satisfied that of a target or non-target particle, the image-processing unit switched the DC voltage between the gel electrodes of the cell-sorter chip by switching the DC power supply on or off in real time.

4.2 Real-time size-discrimination of two particles close in size using microscopic images and improvement of depth of field using zoom lens optics for deeper microfluidic pathways

To evaluate the image-recognition ability of the cytometry system, we used a mixed suspension containing polystyrene particles close in size ( 2.5 or $3.0 \mu \mathrm{m}$ in diameter) (Fig. 15). Their images were clear, but the sizes were hard to discriminate with the human eye without a scale or a size-comparison object (Fig. 15a-b). However, the image recognition unit of the cytometry system discriminated between the two sizes with an error rate of less than $2 \%$ at $200 \mathrm{frames} / \mathrm{s}$ in real time at a flow velocity of $10 \mathrm{~mm} / \mathrm{s}$ (Fig. $15 \mathrm{c}-\mathrm{e}$ ). For a mixture of $5-$ and $10-\mu \mathrm{m}$ polystyrene particles, the error rate was less than $1 \%$ at a flow velocity of $200 \mathrm{~mm} / \mathrm{s}$. For a mixture containing particles with various specific diameters, the error rate increases with the flow velocity (Hattori and Yasuda 2012; Hattori et al. 2011). These results suggest that imaging cytometry has many advantages for precise and high-throughput separation of target cells from undesired cells with a difference in size that is difficult to discriminate with the human eye.
We also examined the resolution of the depth of field when the height of a polystyrene bead was changed in an inverted microscope (Olympus IX70) with three objective lenses [Olympus UPlanFl 10× $(\mathrm{NA}=0.3)$; LCPlanFl 20× (0.4); LCPlanFl $40 \times(0.6)$ ]. Figure $16 \mathrm{a}-\mathrm{c}$ show micrographs of a $15-\mu \mathrm{m}$ bead acquired with the zoom optics (10× objective lens plus zoom optics) and with the inverted microscope for every $5-\mu \mathrm{m}$ depth at total magnifications of $10 \times, 20 \times$, and $40 \times$ (upper micrographs) and with $10 \times, 20 \times$, and $40 \times$ objective lenses (lower micrographs). The total magnifications of the optics were adjusted by changing the zoom ratio in the zoom optics and exchanging the objective lenses in the inverted microscope. There was almost no variation in the hues of the bead at bead depths of $0-25 \mu \mathrm{m}$ in the zoom optics. In contrast, defocusing increased with the bead depth in the microscope images. The amount of focus change was particularly large at magnifications of $20 \times$ and $40 \times$. From the results shown in Fig. 16, the depth of field was estimated to be $25 \mu \mathrm{m}$ or greater at any magnification in the zoom optics. It was estimated to be $15 \mu \mathrm{m}$ at $10 \times$ and $5 \mu \mathrm{m}$ at $20 \times$ and $40 \times$ in the microscope images. These results indicate that the depth of field is improved at any magnification from $10 \times$ to $40 \times$ and that an extended depth of field optics for imagebased microfluidic pathways (i.e., wider depth resolution in deep microfluidic pathways) can be constructed using a low NA objective lens and a zoom lens.

\subsection{Indexes acquired from imaging flow cell-sorting system}

As described above, the parameters of a particle's image, including the mean intensity, the area, the lengths of the major and minor axes, and the degree of circularity, were 
Fig. 22 Configuration of ultra-high-speed real-time $\mu 1$ sample droplet PCR module: a schematic image and b photograph

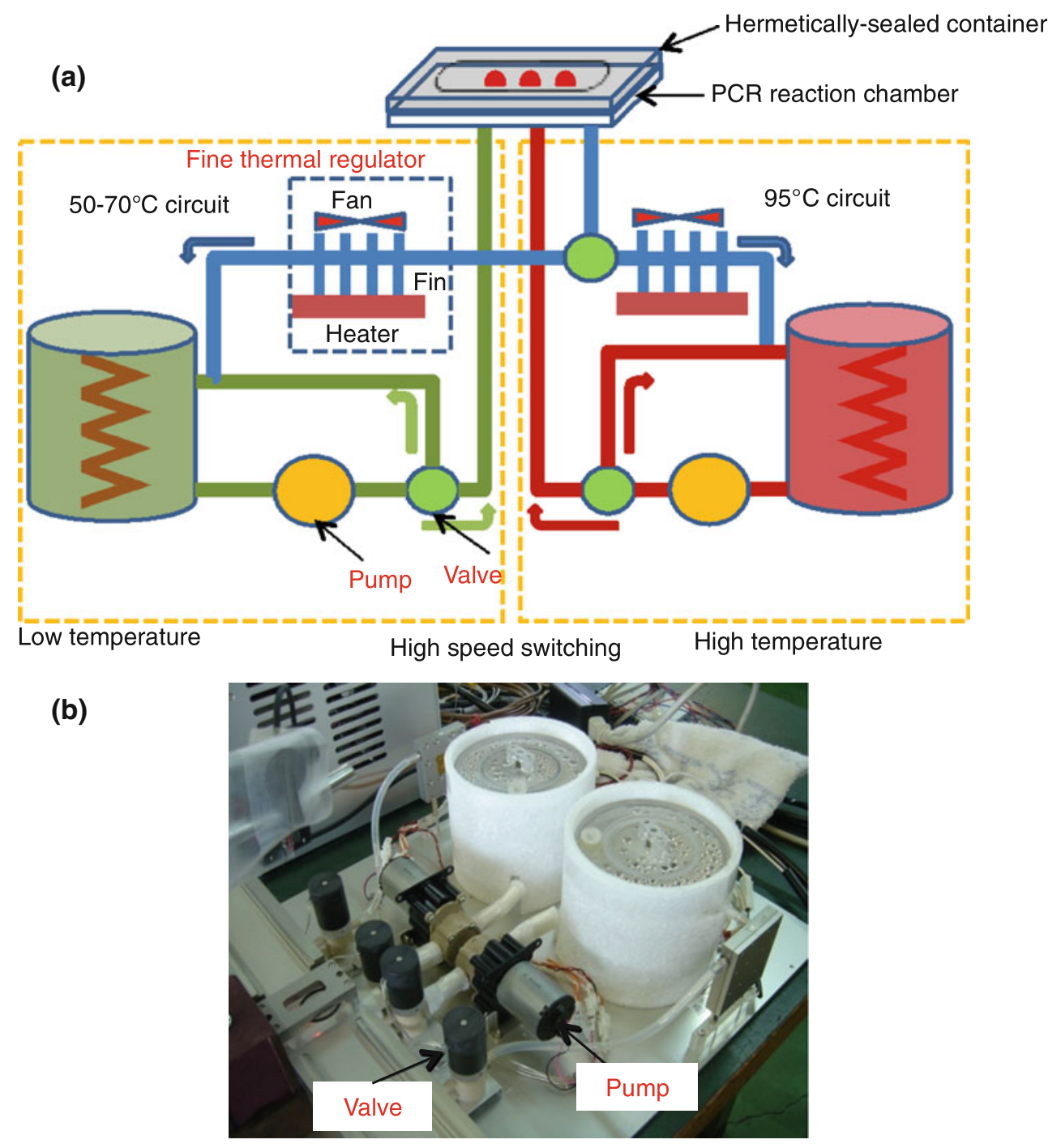

calculated about the pixel value (Fig. 14). Figure 17a shows example data analyzed using the calculated parameters. The analyzed roundness and size of each cell image was plotted, and the original images were stored on a hard disk drive and cross-referenced to the plots. This enabled detailed images from the plotting to be called up and used for checking detailed shapes of samples. Figure 17b shows examples of acquired micrographs in which multinucleated cells and M-phase cells were identified, illustrating one of the advantages of imaging flow cell sorting compared to conventional diffraction-based cell identification analysis.

\subsection{Purification of cardiomyocytes using index of cell surface roughness}

In imaging flow cell sorting, the particular index of each cell image is essential for separating the images. Previous examination showed that most of the round smooth cells in a mixture containing cardiomyocytes are cardiomyocytes
(Kaneko et al. 2011). We thus defined index $R$ of cell surface roughness for use in comparing the actual and estimated cell surface perimeters by approximation of a spherical model, enabling the surface roughness of cardiomyocyte cells and other cells to be distinguished quantitatively.

$R=\frac{l}{\sqrt{4 \pi S}}$,

where $l$ is the cell surface perimeter, and $S$ is the cell cross-sectional area (both $l$ and $S$ are acquired from pixelbased digitized-image cell analysis). For example, a cell with reduced radius $r$ has $R\left(=2 \pi r /\left(4 \pi \times \pi r^{2}\right)^{1 / 2}\right)$ equal to 1 , and a cell with higher roughness and thus a larger perimeter has a proportionally larger $R$. Index $R$ is used to quantify the smoothness or roughness of cell surfaces. Smooth cells typically have an $R$ less than 1.1 (Fig. 18a), and rough cells typically have an $R$ larger than 1.1 (Fig. 18b). 
(a)

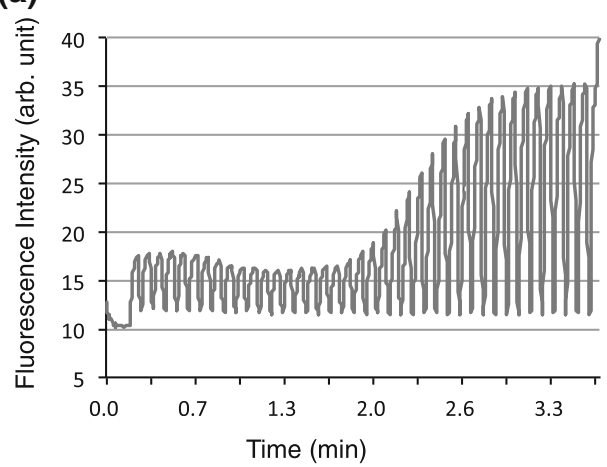

(b)

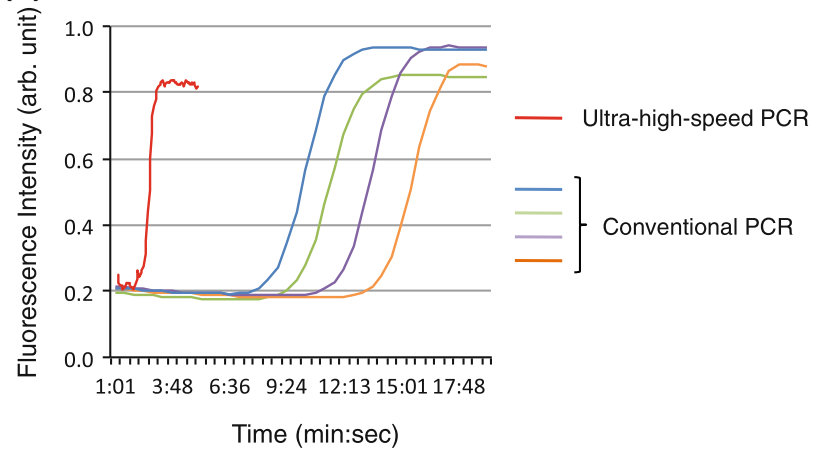

Fig. 23 a Results of ultra-high-speed real-time PCR amplification, b comparison between ultra-high-speed PCR and conventional PCR (air-thermo PCR instruments) (reproduced from Terazono et al. 2010)

There are two major requirements for achieving nonlabeled separation of cardiomyocyte cells from a mixture of enzyme-treated heart extracts. One is the development of a reliable index for quantifying the surface roughness of cells for use in distinguishing the target cells, and the other is the development of an enzymatic method for visualizing the differences in surface shape for use in distinguishing individual cells.

Experience has shown that the collagenase-digestion process is effective in cardiomyocyte purification for distinguishing between smooth and rough cell surfaces and thus distinguishing between cell types. This process must be followed by incubation for at least $20 \mathrm{~min}$ before cell sorting for the differences between smooth and rough surfaces to be distinguishable. With the conventional trypsinization cell preparation procedure, the differences between smooth and rough surfaces are indistinguishable.

In an experiment, a sample mixture of cells was acquired from collagenase-digested heart tissue isolated from 13-day-old mouse embryos, and the cell-sorting system was used to distinguish the smooth surface cells (Fig. 18a) from the rough surface cells (Fig. 18b). Index $R$ for the smooth cells was 1.08 or less, and that for the rough cells was greater than 1.1. These results show that an $R$ value of 1.1 is a suitable threshold for distinguishing smooth and rough surface cells in our on-chip imaging flow cell-sorting system.

Using this index and our label-free on-chip imaging flow cell-sorting system, we succeeded in separating cardiomyocyte cells. As shown in Table 2, of the 242 smooth cells, $178(73.6 \%)$ were beating cells, $19(7.9 \%)$ were non-beating cells, $12(5.0 \%)$ were shrunk cells, and 33 (13.6\%) were unattached cells (Table 2). There were 195 cardiac myosin positively stained cells $(99.99 \%$ of healthy cultivated cells; $80.6 \%$ of all collected smooth cells), and there were two negatively stained cells $(0.01 \%$ of healthy cultivated cells; $0.8 \%$ of all cells). This means that more than $80 \%$ of the smooth cells were beating cardiomyocyte cells and that more than $99 \%$ of the healthy recultivated cells were cardiomyosine positive cells. These results suggest that non-labeling simple phase-contrast imagebased cell sorting using the index of cell surface roughness can potentially be used to separate cardiomyocyte cells from a mixture of heart cells with an error rate of less than $1 \%$ (Nomura et al. 2011).

\section{Application of imaging cell sorter}

\subsection{Selection of membrane filter for preventing contamination}

The transfer of sorted cells from the cell-sorting chip into a culture vessel involves the risks of cell contamination, damage, and loss. To overcome these risks, we developed an on-chip culture system using a PMMA-based cell-sorting chip. Although the sorted cells in the cell-sorting chip can be cultured by transferring the whole chip into an incubator, there is still the risk of contamination because the medium in the outlet tubes is exposed to outside air. Moreover, since the two or three outlet tubes on the cellsorting chip are linked by the culture medium, waste cells and/or particles can contaminate the collection outlet due to convection or self-propulsion during cultivation. To prevent such contamination, we need to isolate the outlet tubes from the downstream reservoir using a membrane filter. The membrane filter needs to be permeable to nutrients and gasses and impermeable to cells and bacteria. A tight seal between the edge of each outlet tube and the filter is created by thermal bonding. Since the softening point of PMMA is about $100{ }^{\circ} \mathrm{C}$, the filter should have resistance at the temperature used for thermal bonding. The membrane surface must be ruck-free to achieve tight sealing. For the filter to be permeable to nutrients and gasses, the membrane must have good hydrophilia. The filter must be transparent to visible light to enable the cells in the outlet tubes to be observed without breaking the seal. We compared the seven commercial membrane filters 


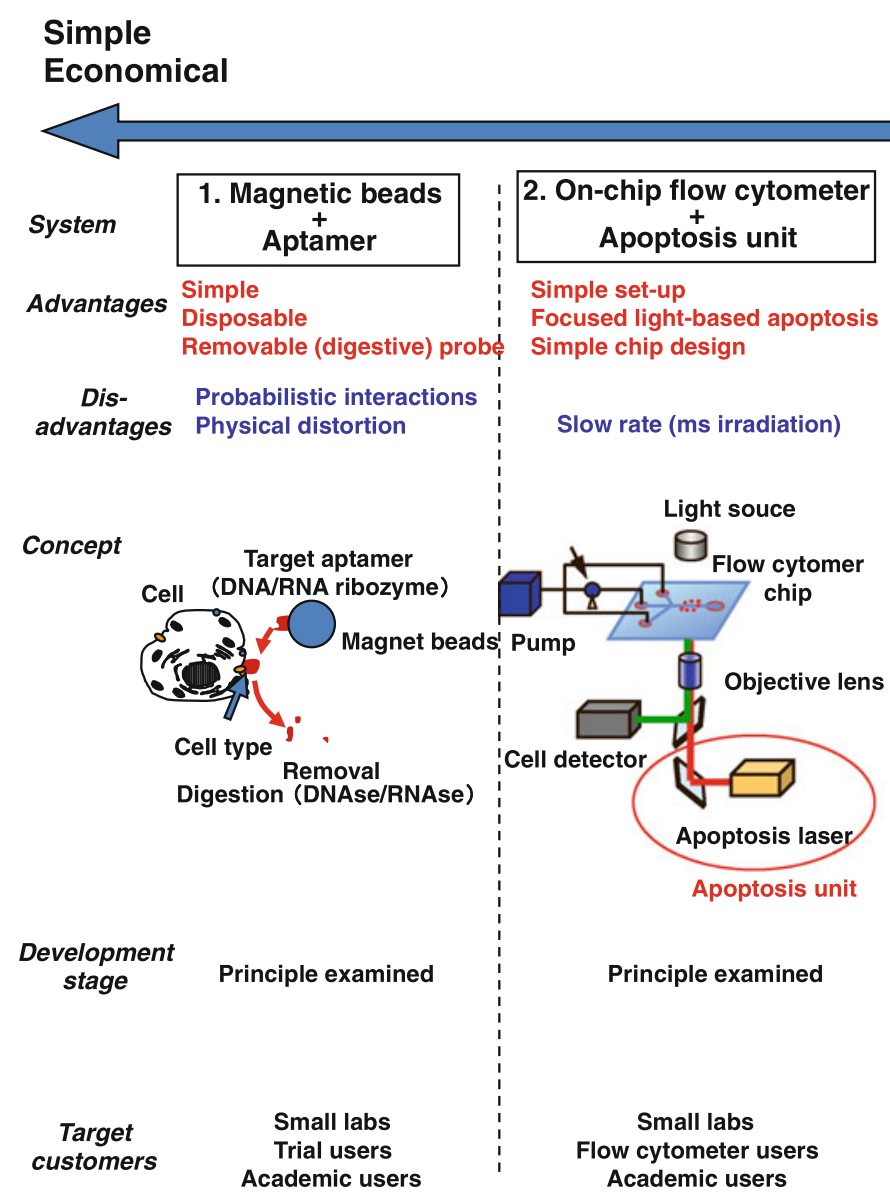

High-performance Expensive

Fig. 24 Comparison of four typical cell-sorting technologies

listed in Table 3 on the basis of these requirements and selected the first four for testing.

We used E. coli to test the permeability of the four selected filters. A sample filter was bonded to the edges of dummy outlet tubes. The Omnipore filter for all pore sizes and the Isopore filter with pore sizes of 0.1 and $0.2 \mu \mathrm{m}$ were not permeable to $E$. coli, while the Isopore filter with pore sizes greater than $0.4 \mu \mathrm{m}$ and the other filters were permeable (Fig. 19).

Given the impermeability of the Omnipore filters to E. coli, we tested their use on our cell-sorter chip (Fig. 20). Cardiomyocyte cells adhered to the bottom of the membrane-sealed outlets and remained beating over 2 days (Fig. 20a-c). Contamination by $E$. coli from the downstream reservoir into the outlet tubes during cultivation was observed for filters with pore sizes of 0.2 and $0.45 \mu \mathrm{m}$ but not for that with $0.1-\mu \mathrm{m}$ pores (Fig. 20d-i). Therefore, the use of a $0.1-\mu \mathrm{m}$-pore Omnipore filter with our PMMAbased cell-sorting chip enables on-chip cultivation without contamination.

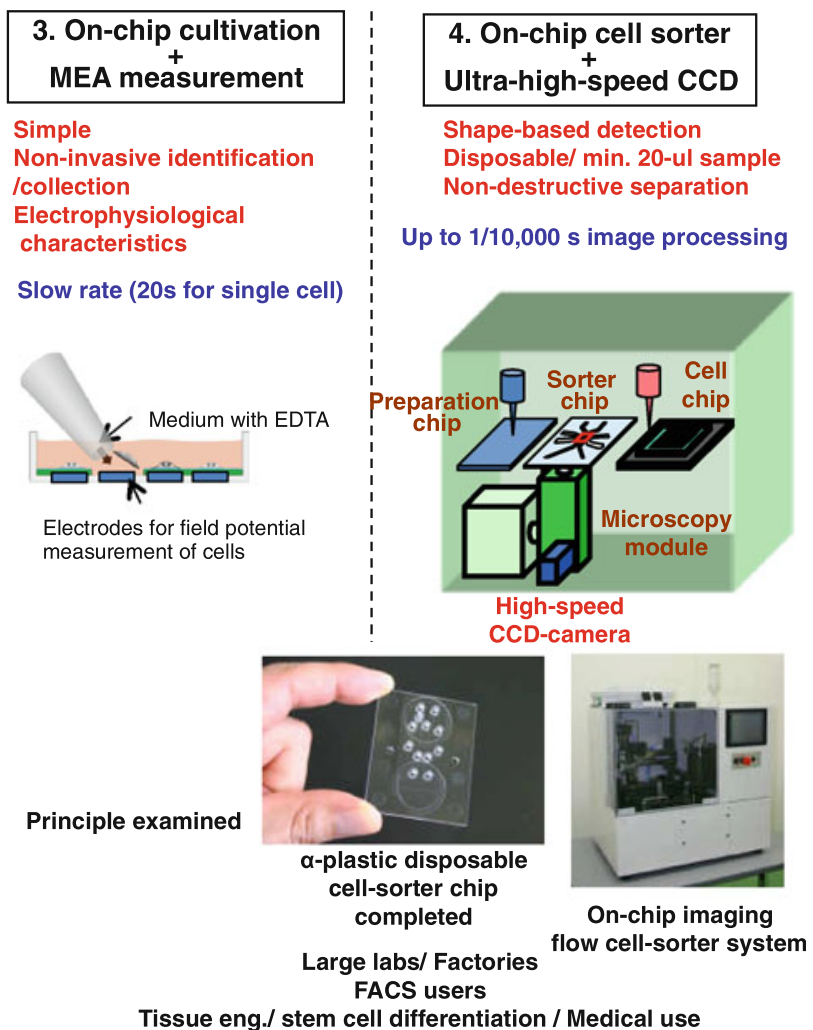

5.2 Integration of cell-sorting system with sample preparation unit and ultra-high-speed droplet PCR module

As illustrated in Fig. 2, one of the final destinations of cell sorting is analysis of the collected target cells. To accomplish this, we combined a stand-alone on-chip imaging flow cell-sorting module with a sample preparation module and an ultra-high-speed droplet polymerase chain reaction (PCR) module in a rack, which serves as an integral loadbearing structure (Fig. 21). Each module carries out a specific task related to rapid nucleotide detection: the sample preparation module concentrates the sample cells, (2) the cell-sorting module sorts the cells on the basis of image analysis, (3) and the PCR module analyzes the cells. A modular approach was taken so as to facilitate upgrading of the individual modules as more advanced ones become available. As shown in Fig. 21b, the modules are arranged in the rack so that they can easily be slid out horizontally for easy access and replacement. 
In the sample preparation module (Fig. 21c-d), $1,000 \mu \mathrm{L}$ of the sample solution is forced through a silicone tube under pressure into a glass vessel. A single silicone tube is reused and is washed between trials. Once the vessel is filled with sample solution, it is pressurized to force the solution through a filter cartridge. This is accomplished by sealing the vessel with a lid equipped with two tubes; pressure is applied through one tube, and the solution is forced out through the second, which is long enough to reach residual fluid at the bottom of the vessel. When the solution is forced through the filter cartridge, particulates are trapped on the filter surface. A dispenser is inserted into the cartridge, and negative pressure is applied to recover these particulates. A filter with a smooth surface punctuated with discrete pores was used to facilitate their removal. It would be more difficult to recover the trapped particulates with a fiber filter. The internal shape of the cartridge was designed so as to minimize the volume between the filter and dispenser. It is important that the amount of fluid used for particulate recovery is kept at a minimum, because the concentration ratio is higher when the amount of recovered fluid is greater. The recovered particulates are transferred to another container that is accessible to the inter-module sample transfer dispenser. This module contains 12 sets of glass vessels, filter cartridges, and dispensers. The vessels are mounted on a rotating turret as are the filter cartridges with their own rotating turret. A dye can be injected into the vessels if the pathogen needs to be labeled. After sample preparation, the cells are transported and sorted in the second module, and the collected target cells are then analyzed in the third module.

DNA/mRNA analysis of the collected cells is done using a newly developed simple ultra-high-speed real-time $\mu l$ sample droplet PCR module featuring rapid water-based heating of sample droplets by quick switching between two hot water circuits (one for denaturation and one for annealing and extension). The module consists of two hot water circuits, a reaction chamber, and a light-fiber fluorescent detector. As shown in Fig. 22, each hot water circuit has a tank with an internal heater, two diaphragm valves, a fine-adjustment heater, a check valve, and a geared pump and is connected to a PCR reaction chamber made of PDMS and containing a thin-film aluminum chip, on which a $3 \times 8$ array of micro indentations are embossed to hold $\mu$ l-sized water droplets. The water in each circuit is circulated continuously by the pump during reaction to maintain the temperature of the hot water in each tank. It is transferred to the reaction chamber only when the temperature of the reaction chamber needs to be increased to that of the hot water. Fine temperature control of the circulated hot water is achieved by adjusting the appropriate fine-adjustment heater. One circuit maintains the water temperature at $95{ }^{\circ} \mathrm{C}$; this water is used for denaturation of DNA fragments. The other maintains the water temperature at $50-70{ }^{\circ} \mathrm{C}$; this water is used for extension of DNA fragments. Diaphragm valves are used simultaneously to control the circulation of the water and to transfer it when needed to the reaction chamber, where it is circulated under the aluminum chip, resulting in direct transfer of the heat from the water to the chip and then to the droplets. When the water is no longer needed, it is returned to the appropriate hot water tank and again circulated.

Rapid PCR amplification of a set of droplets containing Bacillus anthracis lined up on the aluminum chip was evidenced by the increase in fluorescent intensity, as shown in Fig. 23a. It was accomplished using the sample preparation module and on-chip imaging flow cell-sorting module within 3.5 min (40 cycles of 1-s denaturation and 3 -s extension). As shown in Fig. 23b, this is an order of magnitude faster than with a conventional fast PCR system. This integrated system, thus, enables rapid detection of DNA fragments and is potentially applicable to the measurement of multiple samples simultaneously in a miniaturized microfluidic chip.

\section{Discussion}

We can estimate the performance of the imaging flow cellsorting system as follows. Suppose the maximum sampling rate of image acquisition and recognition is 200 events/s and the sorting efficiency is $90 \%$ at a flow rate less than $200 \mathrm{~mm} / \mathrm{s}$ in the cell-sorting area. The cell-sorting area is $50 \mu \mathrm{m}$ wide, $25 \mu \mathrm{m}$ high, and $100 \mu \mathrm{m}$ long. The flow rate in the cell-sorting area is ten times that in the sample inlet because of the sheath structure. The discrimination error is less than $2 \%$ for a mixture of 2.5 - and 3.0- $\mu$ m polystyrene particles. All operations after sample setting are automated and take less than 5 min except for the cell-sorting process.

Since the maximum sampling rate is 200 events/s, the maximum sample-processing rate is $25 \mathrm{~nL} / \mathrm{s}(=50 \mu \mathrm{m}(\mathrm{W})$ $\times 25 \mu \mathrm{m}(\mathrm{H}) \times 100 \mu \mathrm{m}(\mathrm{L}) \times 200$ events/s $)$. Under these conditions, the flow rate in the cell-sorting area is $20 \mathrm{~mm} / \mathrm{s}$ $(=100 \mu \mathrm{m} \times 200$ events/s). For example, $50 \mu \mathrm{L}$ of the sample will be processed within $33 \mathrm{~min}(=50 \mu \mathrm{L} / 25 \mathrm{~nL} / \mathrm{s})$. Therefore, the total operation time is less than $40 \mathrm{~min}$.

Because the unit volume of sample processing is very small (125 pL/event, the volume of the cell-sorting area per event), sample dilution is not necessary for cytometry; the maximum density of sample particles is $8 \times 10^{6}$ particles/mL $(=1 / 125 \mathrm{pL})$. For example, if the sample density is $1 \times 10^{6}$ particles $/ \mathrm{mL}$, which is $1 / 8$ th the maximum density, the sample particles are processed one by one with an entanglement error in cell sorting of less than $0.8 \%$, as shown by the Poisson distribution. 
Therefore, analysis of a $50-\mu \mathrm{L}$ sample at $1 \times 10^{6}$ particles/s requires that the error for discriminating target cells in the collection tube be less than $2 \%$ and that the database of microscopic images be fully accessible within $40 \mathrm{~min}$. This estimated performance demonstrates that our cellsorting system is useful for biological research and clinical diagnosis.

The sorting time could be reduced by increasing the sorting force using improved technology such as an array of agarose gel electrodes (Fig. 8) to increase the effective area of electrostatic force irradiation. The recognition rate could be increased by improving the efficiency of cell sorting.

Figure 24 compares four typical cell-sorting technologies. Magnetic bead-based acquisition of target cells is the most simple and economical (Anzai et al. 2007; Terazono et al. 2010). However, the magnetic-bead interactions with target cells are probabilistic, so the population count is not precise. The on-chip flow cytometer uses the apoptosis phenomenon for cell purification; i.e., infrared laser irradiated cells are removed by apoptosis during cell recultivation. Although this technology is simple and fast, recultivation is essential for purification. The on-chip cultivation technology described in this review combines onchip multielectrode array (MEA) measurement and a digestible polyarginine layer; it performs non-invasive electrophysiological functional identification of target cells and single-cell-level collection and recultivation (Terazono et al. 2012). The on-chip imaging flow cell-sorter system is the non-invasive shape-based detection technology of target cells as we described in this review.

One of the advantages of the on-chip imaging flow cellsorting technology is quick and complete sample measurement based on image information for the samples. In particular, as shown in Figs. 17 and 18, it can obtain detailed information on cell cycles and conditions, which is difficult with conventional diffraction-based cell-sorting technologies. Complete sample measurement is important for estimating the probability of events and populations. Imaging flow cell-sorting technology is thus well suited for detailed analysis of cell groups.

We introduced two potential applications of our on-chip imaging flow cell-sorting: contamination-free recultivation and integrated PCR measurement system. In contrast to conventional flow cytometry, the most important feature of cell-sorting technology is acquisition of target cells from samples. Hence, further cell treatment procedures such as cell recultivation and cell analysis should be considered for practical cell-sorting technology development. We have demonstrated that a membrane filter lid with a disposable cell-sorting chip works well for contamination-free recultivation and that integration of an on-chip imaging flow cell-sorting module with a droplet PCR module enables identification of rod-shaped $B$. anthracis from a crude sample mixture. This means that one of the next steps in cell-sorting technology development should be the development of an integrated system for further cell treatment and analysis.

\section{Summary}

We have developed an on-chip high-speed imaging flow cell-sorting system with five core features: (1) optical image-based real-time cell sorting; (2) inclusion of all the cell-sorting procedures in an economical and disposable (burnable after use) plastic chip; (3) cell separation electrodes consisting of stable and bubble formation-resistant gel electrodes; (4) contamination-free recultivation; and (5) fully automated operation. This system can be modularized and combined with additional cell analysis modules such as a PCR analysis module. Testing demonstrated that cells and fluorescent dyes can be separated using this system. The time required for cell sorting for a $20-\mu \mathrm{L}$ sample with $1 \times 10^{7}$ particles was within $30 \mathrm{~min}$. This simple, safe, fast, and label-free flow cell-sorting system for cell purification is thus practical and potentially useful for biological research and clinical diagnosis.

Acknowledgments This work was supported by the Japan Science and Technology Organization (JST) and the Kanagawa Academy of Science and Technology (KAST).

Open Access This article is distributed under the terms of the Creative Commons Attribution License which permits any use, distribution, and reproduction in any medium, provided the original author(s) and the source are credited.

\section{References}

Anzai Y, Terazono H, Yasuda K (2007) Simple non-invasive cell separation method using magnetic aptamer-conjugated microbeads and nuclease digestion. J Biol Phys Chem 7:83-86

Assenmacher M, Manz R, Miltenyi S, Scheffold A, Radbruch A (1995) Fluorescence-activated cytometry cell sorting based on immunological recognition. Clin Biochem 28(1):39-40

Azuma C, Yasuda K, Tanabe Y, Taniguro H, Kanaya F, Nakayama A, Chen YM, Gong JP, Osada Y (2007) Biodegradation of hightoughness double network hydrogels as potential materials for artificial cartilage. J Biomed Mater Res Part A 81(2):373-380. doi:10.1002/jbm.a.31043

Bonner WA, Hulett HR, Sweet RG, Herzenberg LA (1972) Fluorescence activated cell sorting. Rev Sci Instrum 43(3):404-409

Golan L, Yeheskely-Hayon D, Minai L, Dann EJ, Yelin D (2012) Noninvasive imaging of flowing blood cells using label-free spectrally encoded flow cytometry. Biomed Opt Express 3(6):1455-1464. doi:10.1364/BOE.3.001455

Grover SC, Skirtach AG, Gauthier RC, Grover CP (2001) Automated single-cell sorting system based on optical trapping. J Biomed Opt 6(1):14-22. doi:10.1117/1.1333676

Hatayama T, Yasuda K, Nishiyama E (1994) Characterization of high-molecular-mass heat shock proteins and 42 degrees 
$\mathrm{C}$-specific heat shock proteins of murine cells. Biochem Biophys Res Commun 204(1):357-365. doi:10.1006/bbrc.1994.2467

Hattori A, Yasuda K (2010) Comprehensive study of microgel electrode for on-chip electrophoretic cell sorting. Jpn J Appl Phys 49(6):06GM04

Hattori A, Yasuda K (2012) Extended depth of field optics for precise image analysis in microfluidic flow cytometry. Jpn J Appl Phys 51:06FK05

Hattori A, Umehara S, Wakamoto Y, Yasuda K (2003) Measurement of incident angle dependence of swimming bacterium reflection using on-chip single-cell cultivation assay. Jpn J Appl Phys 42 (Part 2, No. 7B):L873

Hattori A, Moriguchi H, Ishiwata Si, Yasuda K (2004) A $1480 / 1064 \mathrm{~nm}$ dual wavelength photo-thermal etching system for non-contact three-dimensional microstructure generation into agar microculture chip. Sens Actuators B: Chem 100(3):455-462

Hattori A, Kaneko T, Yasuda K (2011) Improvement of particle alignment control and precise image acquisition for on-chip high-speed imaging cell sorter. Jpn J Appl Phys 50:06GL06

Hayashi M, Yasuda K (2010) Simple microfluidic continuous concentration of microparticles with different dielectric constants using dielectrophoretic force in a V-shaped electrode array. Jpn J Appl Phys 49(9). doi:10.1143/JJAP.49.097002

Hayashi M, Hattori A, Kim H, Terazono H, Kaneko T, Yasuda K (2011a) Fully automated on-chip imaging flow cytometry system with disposable contamination-free plastic re-cultivation chip. Int J Mol Sci 12(6):3618-3634. doi:10.3390/Ijms12063618

Hayashi M, Kaneko T, Yasuda K (2011b) Continuous concentration and separation of microparticles using dielectrophoretic force in a V-shaped electrode array. Jpn J Appl Phys 50(6). doi:10.1143/ JJAP.50.06GL03

Herzenberg LA, Sweet RG (1976) Fluorescence-activated cell sorting. Sci Am 234(3):108-117

Hsu CH, Di Carlo D, Chen C, Irimia D, Toner M (2008) Microvortex for focusing, guiding and sorting of particles. Lab Chip 8(12):2128-2134. doi:10.1039/b813434k

Huang CT, Weng CH, Jen CP (2011) Three-dimensional cellular focusing utilizing a combination of insulator-based and metallic dielectrophoresis. Biomicrofluidics 5:044101. doi:10.1063/1.3646757

Hughes MP (2002) Strategies for dielectrophoretic separation in laboratory-on-a-chip systems. Electrophoresis 23(16):2569-2582

Hulett HR, Bonner WA, Sweet RG, Herzenberg LA (1973) Development and application of a rapid cell sorter. Clin Chem 19(8):813-816

Imamura M, Aoki H, Eya K, Murakami T, Yasuda K (1995) Balloon angioplasty before Wheat's operation in a patient with Turner's syndrome. Cardiovasc Surg 3(1):70-72

Inoue I, Wakamoto Y, Moriguchi H, Okano K, Yasuda K (2001a) Onchip culture system for observation of isolated individual cells. Lab Chip 1(1):50-55. doi:10.1039/b103931h

Inoue I, Wakamoto Y, Yasuda K (2001b) Non-genetic variability of division cycle and growth of isolated individual cells in on-chip culture system. Proc Jpn Acad Ser B, Phys Biol Sci 77(8):145-150

Inoue I, Shiomi D, Kawagishi I, Yasuda K (2004) Simultaneous measurement of sensor-protein dynamics and motility of a single cell by on-chip microcultivation system. J Nanobiotechnol 2(1):4. doi:10.1186/1477-3155-2-4

Johnson KW, Dooner M, Quesenberry PJ (2007) Fluorescence activated cell sorting: a window on the stem cell. Curr Pharm Biotechnol 8(3):133-139

Kaneko T, Nomura F, Yasuda K (2011) On-chip constructive cellnetwork study (I): contribution of cardiac fibroblasts to cardiomyocyte beating synchronization and community effect. J Nanobiotechnol 9:21. doi:10.1186/1477-3155-9-21

Kojima K, Moriguchi H, Hattori A, Kaneko T, Yasuda K (2003) Twodimensional network formation of cardiac myocytes in agar microculture chip with $1480 \mathrm{~nm}$ infrared laser photo-thermal etching. Lab Chip 3(4):292-296. doi:10.1039/b304652d

Kojima K, Kaneko T, Yasuda K (2005) Stability of beating frequency in cardiac myocytes by their community effect measured by agarose microchamber chip. J Nanobiotechnol 3(1):4

Liu P, Meagher RJ, Light YK, Yilmaz S, Chakraborty R, Arkin AP, Hazen TC, Singh AK (2011) Microfluidic fluorescence in situ hybridization and flow cytometry (muFlowFISH). Lab Chip 11(16):2673-2679. doi:10.1039/c1lc20151d

Matsumura K, Yagi T, Yasuda K (2003a) Differential analysis of cell cycle stability in chlamydomonas using on-chip single-cell cultivation system. Jpn J Appl Phys 42 (Part 2, No. 7A):L784

Matsumura K, Yagi T, Yasuda K (2003b) Role of timer and sizer in regulation of Chlamydomonas cell cycle. Biochem Biophys Res Commun 306(4):1042-1049. doi:S0006291X03010891

Moriguchi H, Wakamoto Y, Sugio Y, Takahashi K, Inoue I, Yasuda K (2002) An agar-microchamber cell-cultivation system: flexible change of microchamber shapes during cultivation by photothermal etching. Lab Chip 2(2):125-132. doi:10.1039/b202569h

Moriguchi H, Takahashi K, Sugio Y, Wakamoto Y, Inoue I, Jimbo Y, Yasuda K (2004) On-chip neural cell cultivation using agarosemicrochamber array constructed by a photothermal etching method. Electrical Engineering in Japan 146(2):37-42

Nomura F, Kaneko T, Hattori A, Yasuda K (2011) Label-free shapebased selection of cardiomyocytes with on-chip imaging cell sorting system. J Bioproces Biotechniq S:3. doi:10.4172/21559821.S3-003

Ogawa T, Sakata S, Nakamura S, Takuno H, Matsui I, Sarui H, Yasuda K (1994) Thyroid hormone autoantibodies in patients with Graves' disease: effect of anti-thyroid drug treatment. Clinica Chimica Acta: Int J Clin Chem 228(2):113-122

Owen CS, Sykes NL (1984) Magnetic labeling and cell sorting. J Immunol Methods 73(1):41-48

Sawaki J, Tsutsui H, Hayashi N, Yasuda K, Akira S, Tanizawa T, Nakanishi K (2007) Type 1 cytokine/chemokine production by mouse NK cells following activation of their TLR/MyD88mediated pathways. Int Immunol 19(3):311-320. doi:10.1093/ intimm/dx1148

Schonbrun E, Gorthi SS, Schaak D (2012) Microfabricated multiple field of view imaging flow cytometry. Lab Chip 12(2):268-273. doi:10.1039/c1lc20843h

Sugio Y, Kojima K, Moriguchi H, Takahashi K, Kaneko T, Yasuda K (2004) An agar-based on-chip neural-cell-cultivation system for stepwise control of network pattern generation during cultivation. Sens Actuators B: Chem 99(1):156-162

Suzuki I, Sugio Y, Jimbo Y, Yasuda K (2004a) Individual-cell-based electrophysiological measurement of a topographically controlled neuronal network pattern using agarose architecture with a multi-electrode array. Jpn J Appl Phys 43B(3):L403-L406

Suzuki I, Sugio Y, Moriguchi H, Jimbo Y, Yasuda K (2004b) Modification of a neuronal network direction using stepwise photo-thermal etching of an agarose architecture. J Nanobiotechnol 2(1):7. doi:10.1186/1477-3155-2-7

Takahashi K, Orita K, Matsumura K, Yasuda K (2003) On-chip microcultivation chamber for swimming cells using visualized poly(dimethylsiloxane) valves. Jpn J Appl Phys 42(Part 2, No. 9A/B):L1104

Takahashi K, Hattori A, Suzuki I, Ichiki T, Yasuda K (2004) Nondestructive on-chip cell sorting system with real-time microscopic image processing. J Nanobiotechnol 2(1):5. doi:10.1186/ 1477-3155-2-5

Takahashi H, Yotsuyanagi H, Yasuda K, Koibuchi T, Suzuki M, Kato T, Nakamura T, Iwamoto A, Nishioka K, Iino S, Koike K, Itoh F (2006) Molecular epidemiology of hepatitis A virus in metropolitan areas in Japan. J Gastroenterol 41(10):981-986. doi: 10.1007/s00535-006-1888-9 
Terazono H, Anzai Y, Soloviev M, Yasuda K (2010) Labelling of live cells using fluorescent aptamers: binding reversal with DNA nucleases. J Nanobiotechnol 8(1):8

Terazono H, Kim H, Hayashi M, Hattori A, Nomura F, Kaneko T, Yasuda K (2012) A non-destructive culturing and cell sorting method for cardiomyocytes and neurons using a double alginate layer. PLoS ONE 7(8):e42485. doi:10.1371/journal.pone.0042485

Umehara S, Wakamoto Y, Inoue I, Yasuda K (2003) On-chip single-cell microcultivation assay for monitoring environmental effects on isolated cells. Biochem Biophys Res Commun 305(3):534-540

Unni HN, Hartono D, Yung LYL, Ng MML, Lee HP, Khoo BC, Lim KM (2012) Characterization and separation of Cryptosporidium and Giardia cells using on-chip dielectrophoresis. Biomicrofluidics 6:012805. doi:10.1063/1.3671065

Urdaneta M, Smela E (2007) Multiple frequency dielectrophoresis. Electrophoresis 28(18):3145-3155. doi:10.1002/Elps.200600786

Wakamoto Y, Inoue I, Moriguchi H, Yasuda K (2001) Analysis of single-cell differences by use of an on-chip microculture system and optical trapping. Fresenius' J Anal Chem 371(2):276-281

Wakamoto Y, Umehara S, Matsumura K, Inoue I, Yasuda K (2003) Development of non-destructive, non-contact single-cell based differential cell assay using on-chip microcultivation and optical tweezers. Sens Actuators B: Chem 96(3):693-700

Wu LQ, Yung LYL, Lim KM (2012) Dielectrophoretic capture voltage spectrum for measurement of dielectric properties and separation of cancer cells. Biomicrofluidics 6:014113. doi: $10.1063 / 1.3690470$
Yamashita R, Fujiwara Y, Ikari K, Hamada K, Otomo A, Yasuda K, Noda M, Kaburagi Y (2007) Extracellular proteome of human hepatoma cell, HepG2 analyzed using two-dimensional liquid chromatography coupled with tandem mass spectrometry. Mol Cell Biochem 298(1-2):83-92. doi:10.1007/s11010-006-9354-9

Yasuda K (2000) Non-destructive, non-contact handling method for biomaterials in micro-chamber by ultrasound. Sens Actuators B: Chem 64(1-3): 128-135

Yasuda K, Okano K, Ishiwata S (2000) Focal extraction of surfacebound DNA from a microchip using photo-thermal denaturation. Biotechniques 28(5):1006-1011

Yasuda K, Roneker KR, Miller DD, Welch RM, Lei XG (2006) Supplemental dietary inulin affects the bioavailability of iron in corn and soybean meal to young pigs. J Nutr 136(12):3033-3038

Yoon YE, Chang SA, Choi SI, Chun EJ, Cho YS, Youn TJ, Chung WY, Chae IH, Choi DJ, Chang HJ (2011) The absence of coronary artery calcification does not rule out the presence of significant coronary artery disease in Asian patients with acute chest pain. Int J Cardiovasc Imaging. doi:10.1007/s10554-0119819-0

Zborowski M, Chalmers JJ (2005) Magnetic cell sorting. Methods Mol Biol 295:291-300

Zborowski M, Chalmers JJ (2011) Rare cell separation and analysis by magnetic sorting. Anal Chem 83(21):8050-8056. doi: $10.1021 / \mathrm{ac} 200550 \mathrm{~d}$ 